\title{
Fosildiagénesis del anélido Rotularia spirulaea (Lamarck, 1818) (Polychaeta, Serpulidae) en el Eoceno del dominio pirenaico occidental
}

\author{
Javier ELORZA ${ }^{1^{*}}$ \& Humberto ASTIBIA ${ }^{2}$
}

\author{
${ }^{1}$ Departamento de Mineralogía y Petrología, Facultad de Ciencia y Tecnología, Universidad del País Vasco/Euskal Herriko \\ Unibertsitatea (UPV/EHU), Apartado de correos 644, 48080 Bilbao \\ ${ }^{2}$ Departamento de Estratigrafía y Paleontología, Facultad de Ciencia y Tecnología, Universidad del País Vasco/Euskal Herriko \\ Unibertsitatea (UPV/EHU), Apartado de correos 644, 48080 Bilbao \\ * Corresponding author
}

Elorza, J. \& Astibia, H. 2018. Fosildiagénesis del anélido Rotularia spirulaea (Lamarck, 1818) (Polychaeta, Serpulidae) en el Eoceno del dominio pirenaico occidental. [Fossildiagenesis of the annelid Rotularia spirulea (Lamarck, 1818) (Polychaeta, Serpulidae) from the Eocene of the western Pyrenees]. Spanish Journal of Palaeontology, 33 (2), 299-320.

Manuscript received 25 July 2018

Manuscript accepted 1 October 2018

(C) Sociedad Española de Paleontología ISSN 2255-0550

\section{RESUMEN}

Se constata la presencia de fósiles del poliqueto tubícola Rotularia spirulaea (Lamarck, 1818), en materiales del Eoceno (Luteciense medio-Bartoniense superior y (?) Priaboniense), pertenecientes al dominio pirenaico occidental y se lleva a cabo un estudio fosildiagenético de los mismos. El estudio se ha realizado con fósiles de tres áreas de ambientes sedimentarios diferentes. En el área 1, correspondiente a la Cuenca de Pamplona (Navarra), Fms. Areniscas de Ardanatz y Margas de Ilundain, los ejemplares de R. spirulaea no han sufrido remoción tafonómica y conservan la microestructura inicial del tubo carbonatado, constituido por una capa externa gruesa, compuesta por tres zonas en continuidad y otra capa interna de una extrema delgadez. El lumen del tubo ha sido rellenado por un fino sedimento y/o cementado por calcita. En el área 2, que engloba la localidad de Anderatz y varios afloramientos de la sierra de Urbasa (Navarra), Formación Urbasa-Andia y depósitos suprayacentes, y en el área 3, emplazada en la parte superior del flysch calciclástico de Punta Galea (Bizkaia), los fósiles se incluyen en sedimentos asociados a ambientes de mayor energía. Aquí la microestructura del tubo de $R$. spirulaea se reconoce de manera incompleta al haber sufrido, durante la diagénesis

\begin{abstract}
The presence of the fossil polychaete Rotularia spirulaea (Lamarck, 1818) in Eocene deposits (middle Lutecian upper Bartonian and (?) Priabonian) belonging to the western Pyrenean Domain is verified. In this paper, a fossildiagenetic study has been carried out. Fossils from three areas, corresponding to different depositional settings, have been analysed. In area 1, sediments of the Ardanatz Sandstone and Ilundain Marls formations [Pamplona Basin and adjoining areas (Navarre)], were sampled. Here, the specimens of $R$. spirulaea were not substantially affected by taphonomic reworking and the original microstructure of the carbonate tube is preserved. The test consists of a thick external shell layer, composed of three zones in succession, and another extremely thin inner shell layer. The lumen of the tube is filled in by fine-grained sediment and/or calcitic cement. In area 2, which includes the town of Anderatz and several outcrops of the Urbasa mountain range (Navarre), UrbasaAndia Formation and overlying deposits, as well as in area $\mathbf{3}$, located on the upper part of the calciclastic flysch of Punta Galea (Biscay), fossils are included in sediments deposited in high-energy environments. In this case, the microstructure of $R$. spirulaea tube is not completely recognized due to intense,
\end{abstract}


temprana una intensa silicificación. El lumen aparece relleno por microrrestos de foraminíferos y algas calcáreas, sedimento cuarzo-feldespático y cementado por calcita. Por tanto, en las zonas 2 y 3 los procesos se alejan sustancialmente de los reconocidos en la zona $\mathbf{1}$, habiendo sido la descripción e interpretación de estas diferencias el principal objetivo de este trabajo.

Palabras clave: Rotularia spirulaea, morfología, fosildiagénesis, Paleógeno, Pirineo. early diagenetic silicification affecting the tests. The lumen is filled in with fragments of foraminifera and calcareous algae, quartz-feldespathic sediment and cemented by calcite. Therefore, in zones $\mathbf{2}$ and $\mathbf{3}$ the fossildiagenetic processes are substantially different from those recognized in zone $\mathbf{1}$. In this paper, the differential preservation of the microstructure depending upon the study areas is described and the diagenetic mechanisms behind these processes are discussed.

Keywords: Rotularia spirulaea, morphology, fossildiagenesis, Paleogene, Pyrenees.

\section{INTRODUCCIÓN, ANTECEDENTES Y OBJETIVOS}

Rotularia Defrance, 1827 es un género extinto de anélido tubícola (Polychaeta, Serpulidae), que posee un tubo carbonatado con un enrollamiento bastante regular, en su mayor parte planiespiral, que no llega a fijarse sobre un sustrato. Hacia la mitad del siglo XX quedó plenamente aceptado que Rotularia era un serpúlido, justificado por las características de la microestructura carbonatada del tubo (para mayor información consultar Savazzi, 1995). El tubo carbonatado posee dos capas o paredes con diferente microestructura (Schmidt, 1955; Ball, 1960; Savazzi, 1995; Vinn, 2008). Para algunos autores el género Rotularia se extiende temporalmente desde el Jurásico Superior (Kimmeridgiense, $157 \mathrm{Ma}$ ) hasta el Eoceno Superior (Priaboniense, 34 Ma) (Ball, 1960; Stevens, 1967; Savazzi, 1995; Jäger, 2005). Para Ippolitov et al. (2014) su rango estratigráfico sería menor; desde el Daniense al Priaboniense (66-34 Ma). Rotularia presenta una distribución global-cosmopolita (Wrigley, 1951; Ball, 1960). Para una mayor información consultar Vinn (2008).

Rotularia spirulaea (Lamarck, 1818), inicialmente atribuida al género Serpula Linnaeus, 1758, es una especie común en los niveles del Eoceno de la Cuenca de Aquitania, en el área norpirenaica (Lamarck, 1818; d'Archiac, 1846, 1850; Rouault, 1850; Bouillé, 1873, 1876). También son reconocidas en muchos enclaves del Eoceno marino del área surpirenaica, desde la región de Vic (nordeste de la Cuenca del Ebro; Abad, 2001), pasando por las Cuencas de Jaca y Pamplona (suroeste de los Pirineos; Carez, 1881; Ruiz de Gaona 1947a; Mendizábal \& Ruiz de Gaona, 1949; Ruiz de Gaona \& Colom, 1950; Astibia et al., 2016) hasta el Eoceno de Cuenca VascoCantábrica (Ruiz de Gaona, 1946). R. spirulaea también se extiende por el dominio del Tetis: Italia (Savazzi, 1995; Vinn, 2008; Accorsi Benini et al., 1992), Croacia (Mikuž, 2008), Hungría (Fozy \& Szente, 2014) y Península de Anatolia (Hoşgör \& Okan, 2006).

Pormenorizando más en la zona de estudio de este trabajo, en la Cuenca de Pamplona (Navarra) sus fósiles son localmente abundantes en los niveles margosos de las formaciones denominadas Areniscas de Ardanatz y Margas de Ilundain, que se superponen y abarcan un lapso temporal Bartoniense - ?Priaboniense inferior, en asociación con macrofósiles de corales, briozoos, moluscos, equinodermos y de otros grupos (Astibia et al., 2014, 2016, 2018). Un primer trabajo sobre $R$. spirulaea en esta zona ha sido realizado por Elorza y Astibia (2017). R. spirulaea también está presente en los niveles del Bartoniense de la cercana área navarra de las sierras de Urbasa y Andia, como se constata en la colección del paleontólogo navarro Máximo Ruiz de Gaona (1902-1971), la cual contiene numerosos ejemplares de $R$. spirulaea inéditos y utilizados en este trabajo. Por otro lado, fue el mismo autor quien escuetamente indicó por primera vez la presencia de fósiles de este anélido en el Sinclinorio de Bizkaia en la zona de Punta Galea (Getxo, Bizkaia) ("asimismo es aqui donde hallo los primeros ejemplares de Sérpula Spirulaea Lamk (sic), muy bien formados y grandes"), sin detallar más, ya que el objetivo principal de su trabajo fue la delimitación del paquete nombrado como "Terciario numulítico fértil (Luteciense inferior, medio y superior)" mediante el estudio del registro fósil de los macroforaminíferos, principalmente de los nummulítidos (Ruiz de Gaona, 1946).

El objetivo de este trabajo es contribuir a un mejor conocimiento de los procesos fosildiagenéticos que han afectado a la especie $R$. spirulaea en las zonas que acabamos de mencionar (Cuenca de Pamplona, área de Urbasa-Andia y área de Punta Galea), ubicadas en el dominio pirenaico occidental, y que corresponden a ambientes sedimentarios notablemente diferentes. Para ello se hace hincapié en: (1) la descripción de la morfología externa del tubo carbonatado original y de las modificaciones sufridas durante los procesos de fosilización, especialmente importantes (como la silicificación) en dos de las zonas de estudio; y (2) estudio de la microestructura esquelética, en sus diferentes capas y subzonas conservadas y de los procesos fosildiagenéticos que han afectado a la misma, además de reconocer los diferentes rellenos y mineralizaciones ocurridas en el lumen de los tubos analizados. 


\section{LOCALIZACIÓN, MATERIAL Y MÉTODOS}

Durante la época del Eoceno el área surpirenaica se estructuró como una cuenca de antepaís orientada al noroeste, adyacente a un orógeno en formación situado al norte (Fig. 1a). Durante la mayor parte del Eoceno la zona permaneció como una estrecha franja de mar entrante desde el Golfo de Bizkaia a unos $35^{\circ} \mathrm{N}$ de paleolatitud. Con el tiempo, los aportes sedimentarios provenientes de la erosión de los Pirineos emergentes fueron rellenando la cuenca. Así, durante el Eoceno medio y superior (Bartoniense y Priaboniense) grandes sistemas sedimentarios fluvio-deltaicos se extendieron por la cuenca de antepaís (Plaziat, 1981; Pujalte et al., 2002; Barnolas et al., 2004).

Esta evolución está bien registrada en una de las áreas de estudio (Área 1), situada en la Cuenca de Pamplona (sinclinal de Aranguren-Itzaga, Navarra), que contiene una serie alternante de unidades litoestratigráficas margosas y arenosas de edades Bartoniense y (?) Priaboniense. La parte inferior de esta sucesión está representada por la Formación Areniscas de Ezkaba, correspondiente a un sistema turbidítico de tipo channel-levee, alimentado directamente desde el orógeno que se alzaba al norte (Payros et al., 1997). Las formaciones suprayacentes, Areniscas de Ardanatz y Margas de Ilundain, representan ambientes de frente deltaico y de plataforma restringida (Astibia et al., 2005, 2014).

Los ejemplares de esta área analizados para este trabajo provienen de las secciones de Ardanatz (Eguesibar) (muestras con las siglas AD), en la transición entre las formaciones Areniscas de Ardanatz y Margas de Ilundain, y del Valle de Itzagaondoa (muestras con las siglas IV), en la parte alta de las Margas de Ilundain (ver Elorza \& Astibia, 2017). La mayoría de los fósiles visibles de $R$. spirulaea se disponen sueltos sobre el regolito generado a partir de las margas, caracterizado morfológicamente por su escasa potencia $(5-10 \mathrm{~cm})$, el agrietamiento poligonal y sus estructuras tipo palomitas de maíz (popcorn). Los lechos de marga buzan ligeramente al sur, dado que los puntos muestreados pertenecen al flanco norte del Sinclinal de Aranguren-Itzaga, y están afectados por una erosión mayor, conformando localmente abruptas laderas acarcavadas (bandlands) (Fig. 1b). Pequeños regueros de escorrentía cortan el regolito y descubren en algún caso fósiles de $R$. spirulaea dispuestos verticalmente en relación a los planos de estratificación (Elorza \& Astibia, 2017).

Una segunda área de estudio (2) se localiza a unos 50 kilómetros al oeste de la primera e incluye un afloramiento de calcarenitas en el enclave de Anderatz (barrio de la población de Abartzuza, Navarra), al norte de la ciudad de Estella-Lizarra, perteneciente a la Formación Urbasa-Andia (Bartoniense inferior, zona SBZ17 de Serra-Kiel et al.,
1998; Payros et al., 2010), y varios puntos en la sierra de Urbasa (Parque Natural de Sierra Urbasa-Andia), a lo largo de la carretera de Olatzagutia-Estella (NA-718), a la altura de los kilómetros 23 (margas y margocalizas, unidad 268, Mapa Geológico de Navarra 1:25.000, geologia.navarra.es), 25 (Fm. Margas de Pamplona, unidad 267) y 28 (calizas con estratificación cruzada, unidad 263, correspondiente a la Formación Urbasa-Andia, Bartoniense inferior, Payros et al., 2010) (Fig. 1c). La formacion Urbasa-Andia se ha interpretado como una rampa carbonatada transgresiva foralgal (macroforaminíferos y algas rojas), dominada por fuertes tormentas como consecuencia del calentamiento global (efecto invernadero) durante el Eoceno medio (Payros et al., 2010).

Los fósiles de $R$. spirulaea de esta segunda área aquí estudiados fueron recolectados a mediados del siglo pasado por Ruiz de Gaona (siglas CRG) y, como se verá más adelante, en ellos resultan visibles varias formas de silicificación. Hace ya más de medio siglo que Ruiz de Gaona (1947b) realizó un estudio del Eoceno de la sierra de Urbasa, recogiendo fósiles de foraminíferos, (nummulítidos, alveolínidos, sorítidos y discociclínidos) en afloramientos situados a la altura de los kilómetros 21 y 30 de la carretera de provincial Olatzagutia-Estella (NA-718). Desconocemos si fue entonces cuando también recogió los ejemplares de $R$. spirulaea, presentados en este trabajo, y los de otros invertebrados (esponjas, moluscos bivalvos, equinodermos equinoideos, artrópodos crustáceos y otros) que se encuentran en su colección, con indicaciones de varios puntos fosilíferos entre los kilómetros 23 y 28 de la misma carretera.

En la actualidad, tanto en Anderatz, debido a roturaciones agrícolas y crecimiento de la vegetación, como en Urbasa, donde asimismo la vegetación se ha debido de espesar a ambos lados de la carretera NA-718, apenas quedan afloramientos prospectables. No obstante, la presencia de fósiles de $R$. spirulaea en la localidad de Anderatz todavía ha podido ser constatada a partir de observaciones recientes sobre el terreno por los autores de este trabajo. Los fósiles de serpúlidos están incluidos en una calcarenita rica en bioclastos, consistentes en restos de macroforaminíferos, briozoos, bivalvos pectínidos y ostréidos, radiolas de equínidos, artejos de crinoides y otros, generalmente en estado muy fragmentario y con rasgos de silicificación (Figs. 1d-e).

La tercera de las áreas estudiadas (3) corresponde al saliente costero de Punta Galea (Getxo, Bizkaia), a unos 90 kilómetros al noroeste del área de Urbasa. Sus materiales, incluidos dentro de la parte superior del llamado Flysch calciclástico (Payros et al., 2006), fueron redepositados en un ambiente de cuenca profunda (deep-marine basinal setting). La zona concreta de estudio se ubica en los acantilados del flanco NE del Sinclinorio de Bizkaia (SB) y los ejemplares de $R$. spirilaea se encuentran englobados en unos potentes depósitos resedimentados formando 


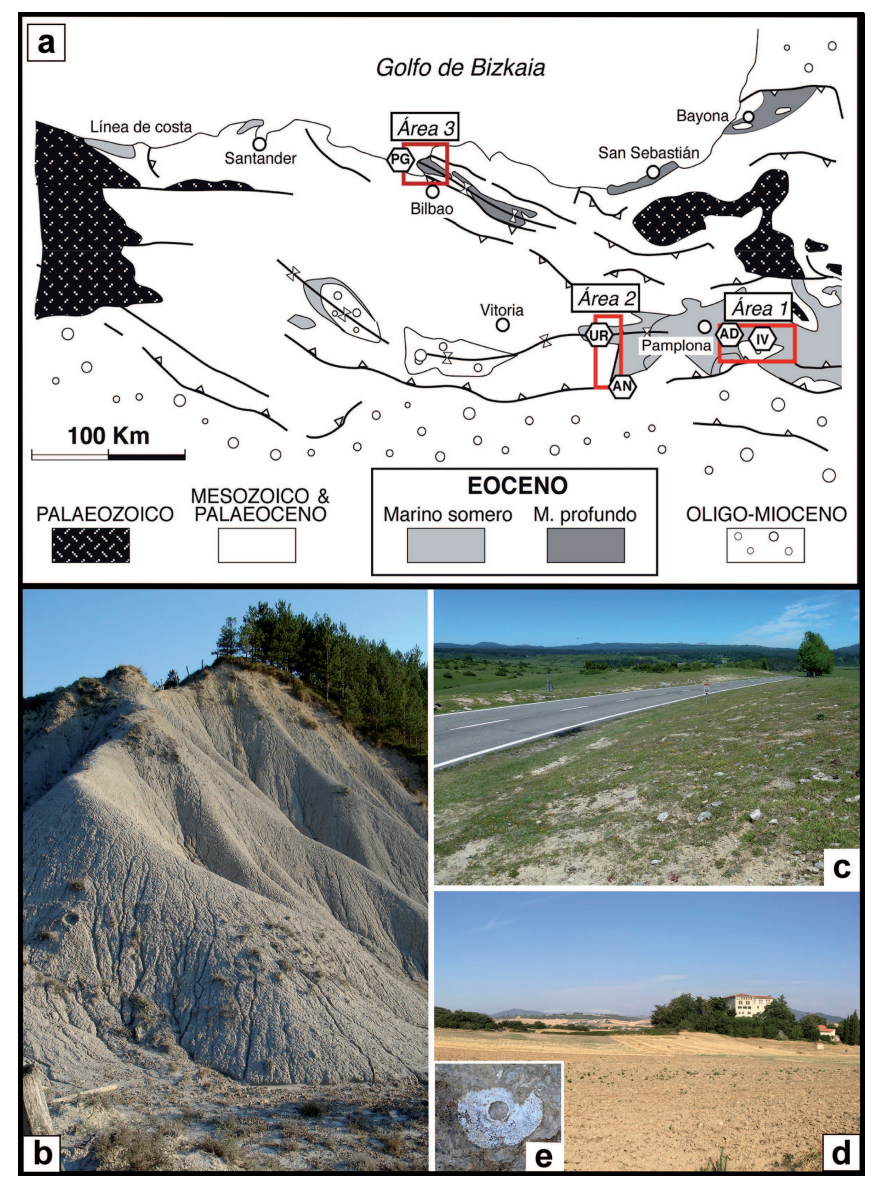

Figura 1. a) Mapa geológico simplificado de las áreas de estudio en la Cuenca de Pamplona (Ardanaz (AD) y valle de Itzagaondoa (VI) (Navarra) (1), Anderatz y sierra de Urbasa (AN-UR, Navarra) (2) y Punta Galea (PG, Getxo, Bizkaia) (3). b) Laderas acarcavadas (badlands) con formación de un delgado regolito en las margas (tufa, en denominación local) de la transición entre las formaciones Areniscas de Ardanatz y Margas de Ilundain, del Bartoniense de la Cuenca de Pamplona, donde han sido recogidos numerosos ejemplares de Rotularia spirulaea (Lamarck, 1818). c-d) Vistas generales de uno de los afloramientos de la sierra de Urbasa (NA-718; Km 23) (c) y de los terrenos de Anderatz (d), de donde proceden algunos de los ejemplares de la colección Ruiz de Gaona estudiados. e) Ejemplar de $R$. spirulaea, detalle de campo en Anderatz. Diámetro del fósil 1,5 cm.

megabrechas, que interrumpen la habitual sedimentación constituida por pares hemipelágicos de marga-caliza (MC), junto con numerosos lechos turbidíticos carbonatados (Pujalte et al., 1997) (Figs. 2a-c). En esta potente sucesión de turbiditas carbonatadas $(>2200 \mathrm{~m})$ de edad Luteciense inferior y medio, están representadas las biozonas de foraminíferos planctónicos Truncorotaloides praetopilensis (Blow) y Globigerinatheka subconglobata (Shutskaya), junto con una pequeña parte de la biozona de Globorotalia (M.) lehneri, Cushman y Jarvis (Orue-Etxebarria et al., 1984; Orue-Etxebarria \& Apellaniz, 1985). Es en la pequeña parte de la biozona de Globorotalia (M) lehneri donde se encuentran las megabrechas (ver Payros et al., 2006). Estas son interpretadas como producto de la actividad sísmica contemporánea con la sedimentación que afectó a extensas áreas de la cuenca, por lo que recogen una mezcla de materiales y fauna característicos de aguas someras de plataforma arrastrados a zonas profundas de Cuenca Vasco-Cantábrica (Pujalte et al., 1997). Posteriormente, durante la orogenia alpina fueron plegados con direcciones de $\mathrm{N} 120^{\circ} \mathrm{E}$, conformando el Sinclinorio de Bizkaia.

Para la descripción de los ejemplares se han seguido principalmente los trabajos de Ball (1960), Savazzi (1995), Macellari (1984), Seilacher et al. (2008) Seilacher \& Gishlick (2014). Para el estudio microestructural se ha utilizado la terminología de Ball (1960). Se ha preparado una selección de 38 láminas delgadas de ejemplares de Rotularia spirulaea en secciones ecuatoriales y transversales, para examinarlas bajo microscopía de luz transmitida mediante una lupa binocular Leica MZ16 equipada con una cámara digital DFC 320, y con un microscopio petrográfico Nikon Labophot T2-Pol acoplado a una cámara Coolpix 4500. Las láminas han sido teñidas con alizarina roja S (siguiendo el método de Dickson, 1965). Para un examen por catodoluminiscencia (CL) se ha utilizado un Technosyn Cold Cathode Luminescence system, modelo $8200 \mathrm{Mk}$ II, montado sobre un microscopio Olympus triocular (UPV/EHU). Dos muestras fueron analizadas por difracción de rayos X (DRX), usando un difractómetro Philips PW-1710 (UPV/EHU). Otras secciones ecuatoriales y transversales han sido empleadas para el examen con el microscopio electrónico de barrido (MEB), utilizando un Jeol JSM-T6400 (UPV/EHU).

Las abreviaturas utilizadas en el texto son: CRG, Colección Ruiz de Gaona; M-C, marga-caliza; DRX, Difracción Rayos X; IV, valle de Itzagaondoa; AN-UR, Anderatz-Urbasa; PG, Punta Galea; RPG, Rotularia Punta Galea; AD, Ardanatz; MEB, Microscopio electrónico de barrido; CL, Catodoluminiscencia; SB, Sinclinorio de Bizkaia.

Los ejemplares estudiados provenientes de la Cuenca de Pamplona y de Punta Galea (áreas 1 y 3), recogidos por los autores firmantes, se encuentran depositados provisionalmente en el Departamento de Estratigrafía y Paleontología de la Facultad de Ciencia y Tecnología de la Universidad del País Vasco/Euskal Herriko Unibertsitatea. Los provenientes de Anderatz y Urbasa (área 2), pertenecientes a la histórica colección Ruiz de Gaona (CRG), se guardan en los Fondos de Arqueología del Servicio de Patrimonio Histórico del Departamento de Cultura, Deporte y Juventud del Gobierno de Navarra. 


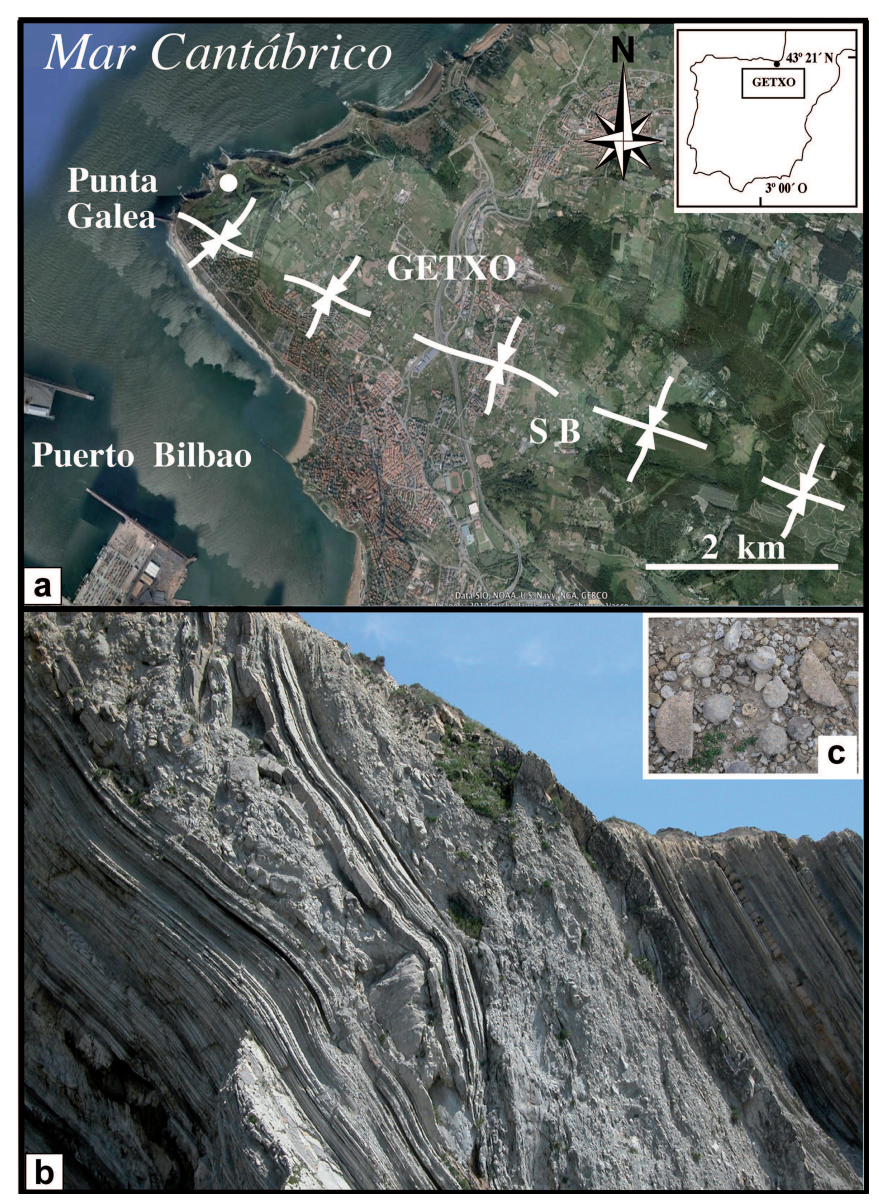

Figura 2. a) Localización geográfica del área 3 correspondiente a Punta Galea (Getxo, Bizkaia), con la zona muestreada (punto blanco). El trazado de líneas blancas discontinuas corresponde al eje del Sinclinorio de Bizkaia (SB). b) Aspecto de la megabrecha principal intercalada en las facies turbiditas carbonatadas de edad Luteciense medio. c) Detalle de la fauna fósil encontrada en la megabrecha donde se mezclan ejemplares de fósiles de nummulites y rotularias silicificados.

\section{MORFOLOGÍA ESQUELÉTICA Y CAMBIOS FOSILDIAGENÉTICOS}

\subsection{Morfología externa}

Las modificaciones encontradas en los ejemplares de $R$. spirulaea, consecuencia de los diferentes ambientes sedimentarios y diagenéticos de donde provienen, hacen conveniente llevar a cabo, en aras de una mejor comprensión del texto, un tratamiento descriptivo individualizado de los mismos por áreas; zonas de estudio que, por otro lado, tampoco son exactamente coetáneas.

\subsection{1. Área 1. Cuenca de Pamplona (Navarra)}

Es aquí donde los fósiles de $R$. spirulaea son más abundantes, presentan menos alteraciones tafonómicas, sin ningúna evidencia de silicificación, lo cual nos permite considerar a estos ejemplares como modeloreferencia, tanto por su morfología externa como por sus características microestructurales. R. spirulaea genera un tubo biomineralizado de naturaleza carbonatada, cuya forma enrollada en espiral ofrece una cierta variabilidad. El inicio o vértice (apex, según Savazzi, 1995) del tubo siempre falta y en la mayoría de los ejemplares le sigue una porción interna de forma troncocónica, correspondiente a un crecimiento helicoespiral, que pasa a planiespiral involuto, de manera más o menos abrupta, tras las primeras vueltas. La marcada y única quilla que se forma no ocupa una posición central sino que está ligeramente desplazada hacia el lado de fijación inicial del vértice del tubo. La porción final del tubo en los ejemplares más grandes (pero también a veces en pequeños) suele estar desenrollada, generándose una chimenea (chimney, según Seilacher et $a l ., 2008)$, formando un ángulo $\left(<45^{\circ}\right)$ con respecto a la porción planiespiral. En esta parte, la quilla se reduce y junto a la abertura la misma desaparece (Figs. 3a-b).

La superficie externa del tubo ofrece finas irregularidades en forma de arrugas y surcos radiales y espirales. En los ejemplares estudiados quedan más o menos patentes los surcos o líneas radiales de crecimiento, correspondientes a las sucesivas fases constructivas o incrementos calcáreos (depósito de lamelas), más bien rectas o ligeramente onduladas, dispuestas con cierta regularidad a lo largo de la porción planiespiral del tubo. En el tubo de algunos ejemplares pueden observarse discontinuidades o resaltes externos marcados que pueden corresponder al desarrollo de peristomas, o bien a la existencia de aparentes fracturas reparadas en vida (Figs. 3a-c). Observadas estas irregularidades en sección ecuatorial, las mismas se reparten a lo largo del tubo pero sin el desplazamiento habitual de las fracturas (Fig. 3d). De manera análoga a como convencionalmente procede Savazzi (1995), con los ejemplares orientados con el vértice hacia arriba, el sentido de enrollamiento de $R$. spirulaea es mayoritariamente levógiro. A los cambios ontogenéticos descritos (crecimiento trocoespiral que pasa a planiespiral $\mathrm{y}$, finalmente, desenrollado), cabe añadir que el tubo presenta un crecimiento anisométrico según los valores obtenidos de diámetro vs. espesor (ver Elorza \& Astibia, 2017).

\subsection{2.Área 2. Anderatz y Sierra de Urbasa (Navarra)}

En esta zonas, ahora roturadas y/ o cubiertas por la vegetación (Figs. 1c-d), se encuentran ejemplares de $R$. spirulaea, incluidos o ya desprendidos de las calcarenitas 


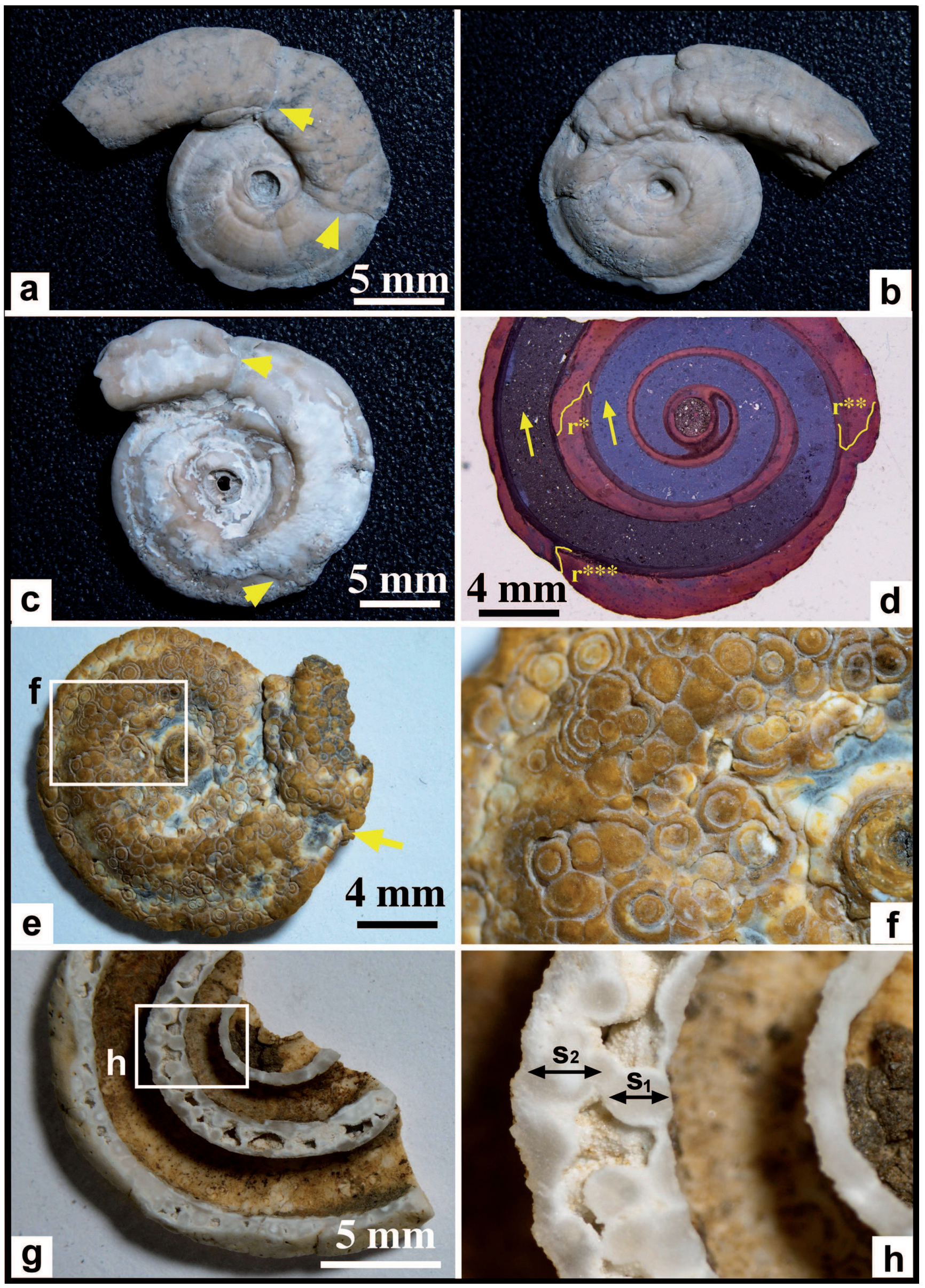


que los encerraban como material transportado, y donde se observa que estos fósiles presentan un intenso grado de silicificación. El reemplazamiento por sílice ha alterado la morfología externa original de los tubos, con formación de conjuntos de anillos de beekita (beekite rings; acuñado en honor a Henry Beeke, Dean de Bristol, 1813-1837, ver Hughes, 1889), que no preservan las arrugas y surcos radiales y espirales de la superficie (Figs. 3e-f). En Urbasa (NA-718, Km 25) el relleno del lúmen normalmente está compuesto por material terroso del suelo actual. Este se pierde en el momento de ser cortado ecuatorialmente el ejemplar, de manera que la cavidad esquelética suele quedar vacía (Figs. 3g-h). Solo excepcionalmente permanece algún resto de cemento carbonatado ocupando el lumen que puede llegar a silicificarse parcialmente, como se comentará más adelante.

\subsection{3. Área 3. Punta Galea (Getxo, Bizkaia)}

Los escasos ejemplares recogidos de R. spirulaea en esta área están asociados a fósiles de nummulítidos, habiendo quedado serpúlidos y macroforaminíferos afectados por una silicificación intensa, hecho que unido a su estado fragmentario impide hacer una descripción morfológica externa precisa de los mismos (Fig. 2c). Los rasgos generales de los tubos observados en sección ecuatorial (forma, tamaño y microestructura) se corresponden con los reconocidos en los ejemplares de la Cuenca de Pamplona (área 1), comentados arriba y extensamente en Elorza \& Astibia (2017).

\subsection{Microestructura}

Para este análisis también se mantiene como modelo la microestructura apenas modificada de los ejemplares de $R$. spirulaea recogidos en la Cuenca de Pamplona (área 1). Mediante el examen de microscopía convencional de las secciones ecuatoriales y transversales, en los mismos se puede reconocer una capa externa gruesa (outer lamellar layer, según Ball, 1960) y otra capa interna extremadamente delgada, sin estructura visible (inner structureless layer), que delimita la forma y tamaño del lumen.

\subsubsection{Capa externa}

La capa externa (1), bien desarrollada, está constituida por tres zonas reconocibles: una zona interna (i) menos gruesa, en continuidad con una delgada zona de inflexión o transición (t) muy oscura que, a su vez, está comunicada con una zona externa (e) de mayor grosor, lo que conforma la superficie exterior del tubo espiral.

Zona interna (i) de la capa externa (1). Destaca por su delgadez en las primeras vueltas de la espira $(<100 \mu \mathrm{m})$, para crecer gradualmente a medida que avanza y llegar a su máximo grosor (300-500 $\mu \mathrm{m})$ en la parte final, donde se produce la porción no enrollada del tubo y consiguiente chimenea (Fig. 4a). En esta zona más gruesa se aprecia a ambos lados del lumen una microestructura aparentemente lamelar, con láminas diferenciadas (claras y oscuras), subparalelas entre sí, que presentan una tendencia a ser asintótica con la capa interna (2), previamente formada (Fig. 4b). También se constata un ahorro de material, al cubrir un amplio espacio con la formación de un sistema de cámaras vacías, mediante el trazado de pilares (p), desde la creciente parte final no enrollada hasta contactar con la zona externa (e) de la vuelta anterior (Fig. 4c). Esta estrategia de formación de pilares (p) también se reproduce en otras partes de la espiral, cuando por la curvatura generada la zona a rellenar resulta demasiado grande.

La supuesta estructura orgánica (¿estipes de algas?), nunca encontrada, a la que se adhiere como anclaje el organismo durante su estadio larvario, queda recubierta con una banda micrométrica carbonática donde no se aprecia su microestructura, aunque bien pudiera corresponder a la capa interna (2) (Fig. 4a). Resulta sintomático que el tamaño y forma de la huella que permanece como estructura de anclaje, es muy semejante en todos los ejemplares examinados.

Figura 3. Rotularia spirulaea (Lamarck, 1818) del área 1 (secciones valle de Itzagaondoa, IV y Ardanatz-Eguesibar, AD), Fm. Margas de Ilundain, transición Fm. Areniscas de Ardanatz-Fm. Margas de Ilundain, (Cuenca de Pamplona, Navarra) y del afloramiento del km 28 de la carretera NA-718, sierra Urbasa, Mapa Geológico de Navarra 1:25.000, del área 2 (CRG) (Anderatz y sierra de Urbasa, Navarra). a-b) Ejemplar IV.62, vistas apical-dorsal (a) y umbilical (b), con posibles peristomas, o bien huellas de readaptación funcional en varias zonas del tubo (flechas amarillas). c) Ejemplar AD2.6 con las mismas características mencionadas en el ejemplar anterior. d) Sección ecuatorial del ejemplar AD1.3 donde se aprecian las posibles alteraciones $\left(\mathrm{r}^{*}, \mathrm{r}^{* *}, \mathrm{r}^{* * *}\right)$ a lo largo del tubo sin aparentemente llegar a producir rotura y desplazamiento. e) Vista externa del ejemplar CRG.4, desprovisto de la fina lámina superficial de carbonato, lo cual permite reconocer la completa silicificación sufrida con anillos concéntricos de beekita y la posible readaptación funcional, señalada por una flecha amarilla. f) Detalle de los anillos con un entramado compacto. g) Ejemplar CRG.5, en sección ecuatorial con el tubo completamente silicificado y el lumen vacío de sedimento y/o cemento. h) Detalle de la imagen anterior, con las secciones esferulíticas de cuarcinalutecita desarrollándose de manera opuesta e independiente a ambos lados del tubo $\left(\mathrm{S}_{1}\right.$ y $\left.\mathrm{S}_{2}\right)$. 


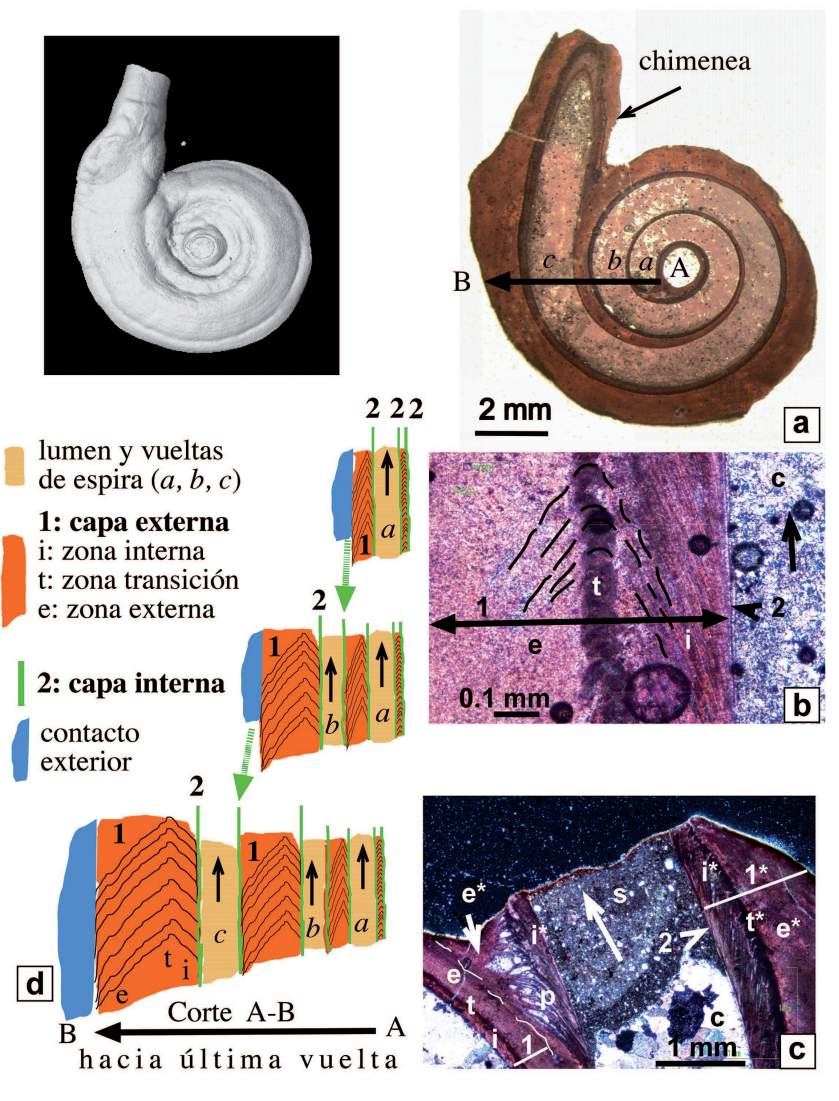

Figura 4. a) Vista general y sección ecuatorial de un ejemplar de Rotularia spirulaea (Lamarck, 1818) del área 1, sección de Itzagaondoa (IV.49), Fm. Margas de Ilundain, (Cuenca de Pamplona, Navarra), donde se aprecian las características de la morfología externa y el trazado regular del tubo con las vueltas de espira $(a, b, c)$, con el espacio del organismo (lumen), ahora ocupado completamente por cemento carbonatado. b) Detalle en sección delgada de la capa externa (1), formada por la zona interna (i), zona de transición (t) y zona exterior (e), además de la capa interna (2), apenas perceptible. La parte derecha corresponde al lumen relleno por cemento carbonatado (c). La flecha negra indica el sentido de enrollamiento de la espira. c) Detalle de la parte del tubo no espiral, relleno de sedimento (s), donde se constata como las zonas nuevas $i^{*}, t^{*}$ y e* de la capa $1^{*}$ se disponen sobre la vuelta anterior señalada por la zona (e), mediante unos pilares (p), que conforman celdas alargadas ocupadas por calcita. La flecha blanca dispuesta en el lumen indica el sentido de enrollamiento de la espira. d) Esquema ilustrativo de la disposición de las capas y zonas, según se van formando las sucesivas vueltas de espira $(a, b, c)$, siguiendo el corte A-B en (a). Nótese como cada nueva vuelta de espira se inicia con la formación de la capa (2) que recubre el lumen. En sección, la misma capa se dispone sobre la zona (e) ya formada, que estuvo en contacto externo con el medio marino (remarcado de azul) y en contacto con la nueva zona (i), en formación y continuidad con las zonas $(\mathrm{t})$ y $(\mathrm{e})$.
En las secciones ecuatoriales se observa mejor la zona de transición ( $\mathrm{t}$ ) entre la zona interna (i) y la externa (e) de la capa externa (1). Ello permite reconocer que, a pesar de la marcada flexión, existe continuidad entre ambas zonas (ie) a través de una alternancia de láminas claras y oscuras, dibujando formas sigmoideas con una mayor concentración de materia originariamente orgánica (parte oscura) en esta zona de transición (t) (Fig. 4b). En la zona de separación del tubo enrollado en planiespiral que da paso a su forma terminal no enrollada se producen uniones de una cierta complejidad, con contactos directos entre la zona externa

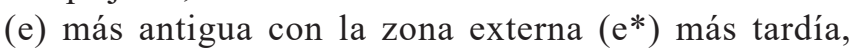
complementados por celdas muy pequeñas, separadas por pilares (p), posteriormente ocupadas por calcita (Fig. 4c).

Resulta sintomático como a lo largo del desarrollo de la espira, se produce un aprovechamiento de lo ya construido, evitando la superposición de una nueva capa externa (1) sobre la capa externa formada anteriormente y ya en contacto con el medio marino. Así, la capa interna (2) (inner vall, según Ball, 1960; fig. 4), se dispone directamente sobre la zona externa (e) de la capa externa (1), perteneciente a la vuelta anterior, sin necesidad de duplicar una nueva capa externa (1), con sus correspondientes subzonas, hasta completar una vuelta de espira. De esta manera, el contacto de las partes blandas del animal con el tubo carbonatado siempre se hace mediante la delgada capa interna (2), que a su vez se dispone tanto sobre la superficie libre de la zona externa anterior como sobre la zona interna en construcción al otro lado del lumen (outer wall e inner wall), tal como queda expresado esquemáticamente (Fig. 4d). Cuando se inicia el desarrollo de la chimenea vuelven a crecer las capas 1 y 2 a ambos lados del lumen (Fig. 3c).

Observadas las diferentes zonas de la capa (1) por el MEB, se confirma cómo la dirección de las líneas de crecimiento reconocidas en la zona externa (e) siempre es contraria a dirección de las líneas de la zona interna (i) por la flexión que se produce en la zona de transición (t) (Figs. 5a-b). Las microestructuras de las zonas interna y de transición (i y t) están formadas mayoritariamente por cristales muy pequeños, aparentemente prismáticos, mientras que el desarrollo de los cristales en la zona (e) es mucho mayor, con una marcada polaridad en su aumento de grosor hacia la parte terminal, conformando una estructura prismática semi-esferulítica (spherulitic prismatic, SphP, según Carter et al., 1990), siempre limitada por sucesivas líneas de interrupción e inicio de otro pulso de crecimiento con las mismas características (Fig. 5b).

\subsubsection{Capa interna}

La capa interna (2) es un revestimiento muy delgado, apenas perceptible, en contacto con el lumen. Observada mediante microscopía convencional no presenta estructura visible y no siempre queda preservada, posiblemente 
debido a su composición inicial nacarada aragonítica. Para Savazzi (1995) la capa interna (inner layer) está compuesta de láminas subparalelas a la superficie interna de la concha y es posiblemente de composición aragonítica y/o rica en materia orgánica, estando parcialmente o totalmente neomorfizada a calcita por la alteración diagenética. En nuestro caso se aprecia esta delgada capa interna (2), ahora de composición calcítica en los ejemplares examinados mediante el microscopio petrográfico. No alcanza las 20-50 micras de grosor y por este medio no es posible determinar su estructura (Figs. 4b-c). Si fuera de composición nacarada aragonítica, muy posiblemente correspondería a una "sheet nacreous structure" (Carter et al., 1990). Las muestras analizadas (dos ejemplares de Ardanatz e Itzagaondoa, respectivamente) mediante difracción de Rayos X, no detectan la presencia de aragonito, siendo dominante la calcita con indicios de cuarzo procedentes del relleno del lumen por un fino sedimento. La observación mediante el MEB, no aporta nuevos datos a los ya conocidos (Fig. 5a).

\subsection{Silicificación esquelética}

Contrariamente a lo que ocurre en el área 1 (Cuenca de Pamplona), donde los cientos de ejemplares examinados de $R$. spirulaea no muestran ningún signo de silicificacion, en las áreas 2 (Anderatz y Sierra de Urbasa) y 3 (Punta Galea) todos los ejemplares se caracterizan porque la microestructura carbonatada del tubo ha sido afectada por un intenso y casi completo proceso de silicificación. Ocasionalmente, también el sedimento emplazado en el lumen se ha visto afectado por este proceso. Por criterios petrográficos en las rotularias fósiles se distinguen dos formas principales de cuarzo autigénico: microcuarzo (tamaño del cristal $<20 \mu \mathrm{m}$ ) y otras variedades fibrosas de la sílice (longitud/anchura $>4$ ) como calcedonia; ya que según su orientación óptica, las fibras pueden ser clasificadas como calcedonita (eje c perpendicular a las fibras), cuarcina (eje c paralelo a las fibras) y lutecita (eje $\mathrm{c} \approx 30^{\circ}$ respecto a las fibras) (Arbey, 1980).

En el área 3 (Punta Galea), la zona más intensamente efectada por la silicificación es la zona externa (e) de la capa externa (1) del tubo. Está formada por un conjunto de botones microesferulíticos de sílice fibrosa (s) del tipo cuarcina-lutecita (Figs. 6a-f), reconocida por su elongación positiva con nícoles cruzados y la lámina de yeso auxiliar (Fig. 6b*). Estos botones son irregulares en su forma, con tamaños que alcanzan dimensiones $<1 \mathrm{~mm}$, en su eje mayor, $\mathrm{y}<0,5 \mathrm{~mm}$, en su eje menor, tendiendo a adquirir un contorno poligonal como resultado de su tendencia estructural al empaquetamiento compacto, sin dejar apenas restos de la microestructura carbonatada original. El proceso se da mayoritariamente en dos frentes de avance individualizados y opuestos $\left(\mathrm{S}_{1}\right.$ y $\left.\mathrm{S}_{2}\right)$, sin aparente prioridad uno del otro, por lo que pueden llegar a coalescer (Figs. 6a-f).

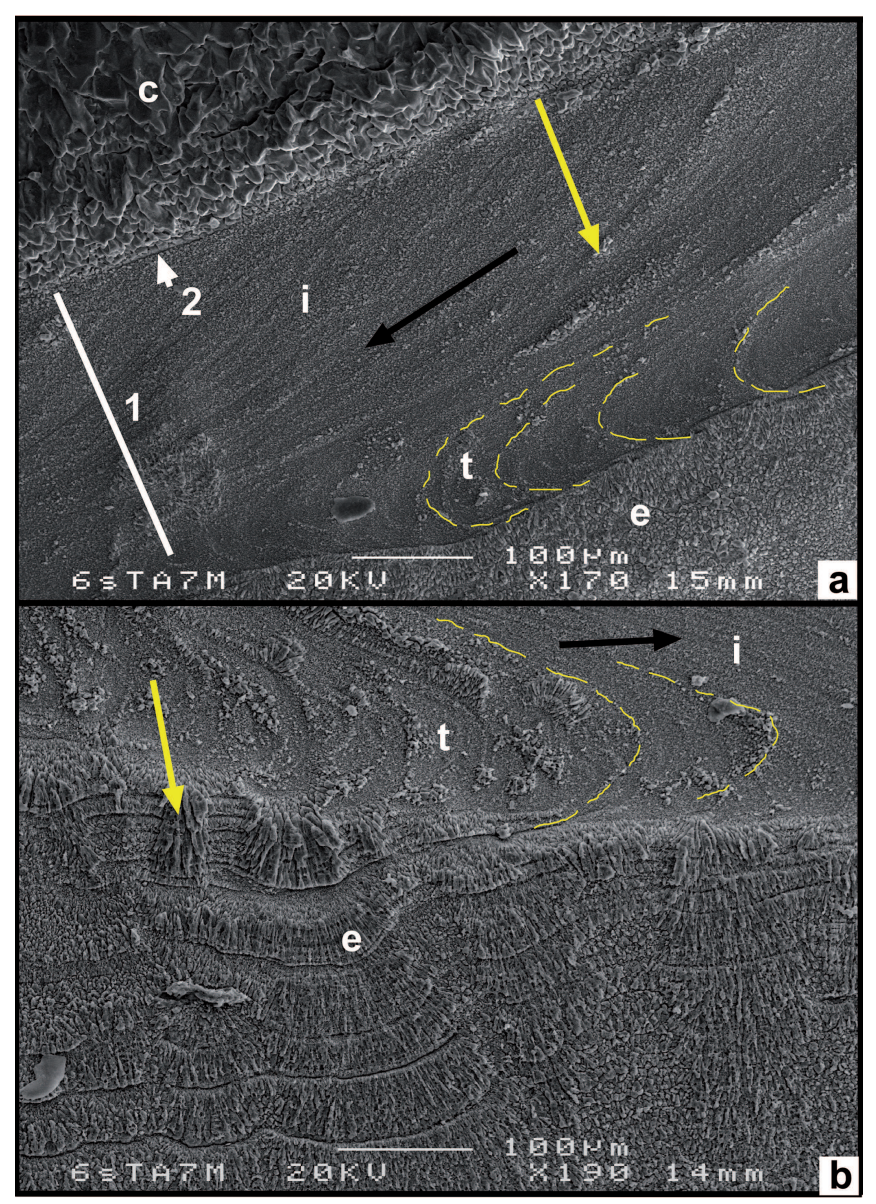

Figura 5. Vista general y de detalle mediante el MEB, de la microestructura del tubo en corte ecuatorial de Rotularia spirulaea (Lamarck, 1818) (AD3.1.17) del área 1, sección de Ardanatz-Eguesibar, transición Fm. Areniscas de Ardanatz-Fm. Margas de Ilundain (Cuenca de Pamplona, Navarra). a) Aspecto general de la capa externa (1) e interna (2) y del relleno espático (c) del lumen. Se aprecian las líneas de crecimiento de la zona interna (i), zona de transición flexionada (t) y la zona externa (e). El tipo de microestructura parece ser prismática, con los prismas muy finos en la zona interna (i), pero con un fuerte aumento de tamaño en la zona (e). La flecha negra indica el sentido de enrollamiento del tubo; la flecha amarilla indica la dirección de crecimiento. b) Detalle del ejemplar AD3.1.18 del área 1 con la microestructura de la zona interna (i) y la zona flexionada ( $t$ ), hasta alcanzar el mayor desarrollo de la zona (e) remarcada por la disposición semi-esferulítica que adoptan los prismas. Estos prismas quedan separados por las líneas de crecimiento y muestran la continuidad entre las tres zonas. La flecha negra y amarilla tienen el mismo significado que en la imagen anterior. 


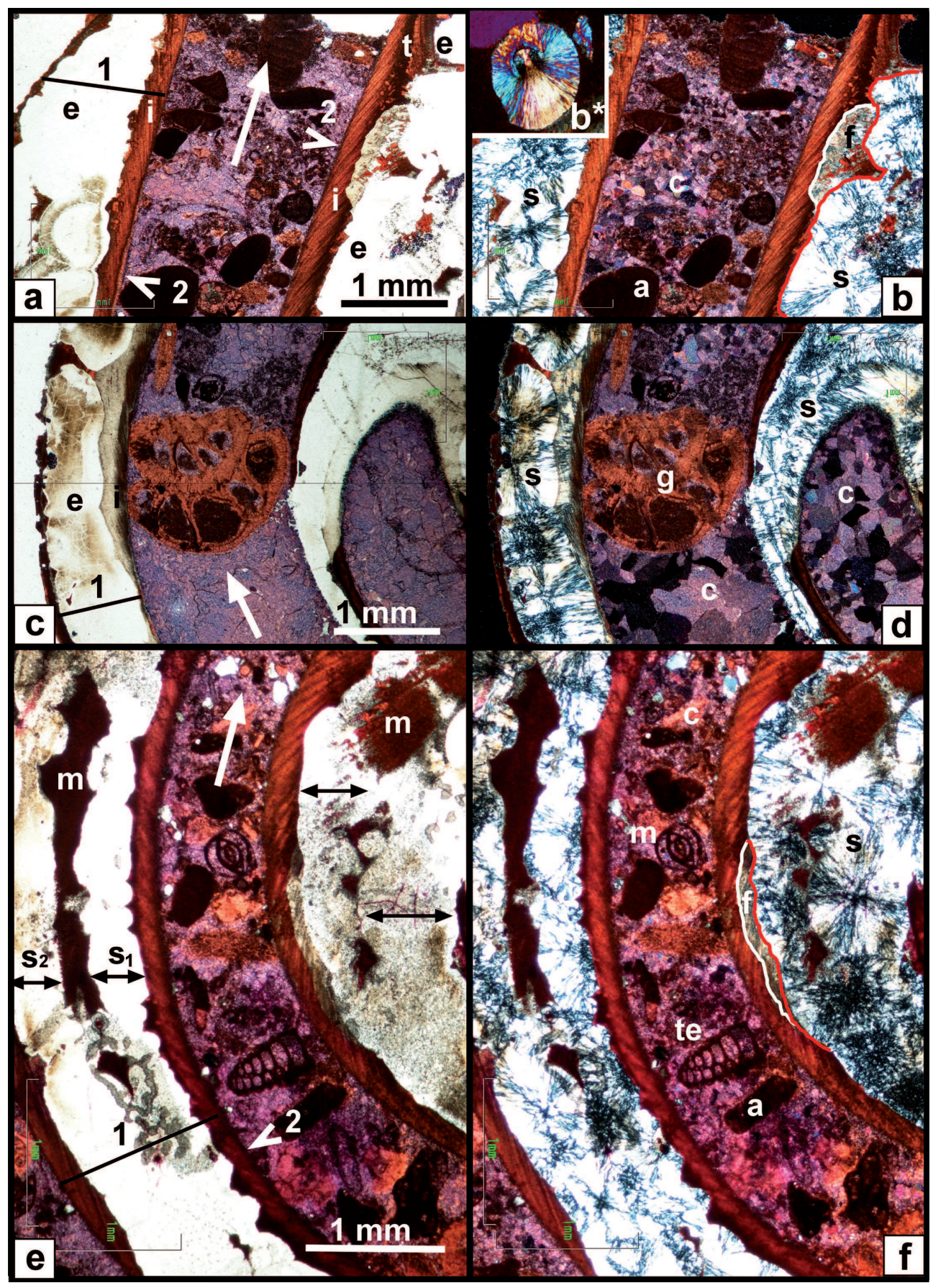

Figura 6. Microestructura del tubo de ejemplares de Rotularia spirulaea (Lamarck, 1818), en sección ecuatorial, recogidos en el área 3, Punta Galea (Getxo, Bizkaia). a-d) Ejemplos complementarios de parte del tubo en espiral del ejemplar RPG.1, donde se aprecia como la silicificación en la capa externa (1) afecta completamente a la zona externa (e) y parte de la zona de transición ( $\mathrm{t}$ ), con esferulitos de cuarcina-lutecita (s), mientras que en la zona interna (i), se produce un fino (f) remplazamiento, conservando las líneas de crecimiento (remarcado entre dos líneas contínuas blanca y roja. La capa interna (2) no silicificada en las figuras (a-b) es apenas perceptible. En el vértice superior izquierdo (Fig. 6b*) se muestra el detalle de un esferulito con elongación positiva (azul), característico de la cuarcina-lutecita. El lumen, sin rasgos de silicificación, queda ocupado parcialmente por bioclastos pertenecientes a Globigerinida ( $\mathrm{g}$ ), y restos micritizados oscuros, además de cemento de calcita en mosaico (equant) (c). Nícoles paralelos (Figs. a, c); nícoles cruzados (Figs. b, d). Las flechas blancas indican el sentido de enrollamiento del tubo. e-f) Ejemplar RPG.2 que presenta una intensa silicificación por esferulitos de cuarcina-lutecita en la capa (1), con dos frentes de avance simultáneos $\left(\mathrm{S}_{1}\right.$ y $\left.\mathrm{S}_{2}\right)$ y con una parte de la microestructura (m) no afectada por la silicificación. Además es visible una silicificación limitada (f), que preserva las líneas de crecimiento originales, remarcadas por una línea blanca y otra roja contínuas. El lumen está ocupado por una importante cantidad de bioclastos (foraminíferos miliólidos, algas calcáreas y organismos micritizados), asociadas a un cemento espático. Nícoles paralelos (e) y cruzados (f). La flecha blanca situada en el lumen indica el sentido de enrollamiento. 
En estos microesferulitos son reconocidos, con nícoles paralelos, zonaciones concéntricas claras y oscuras regidas por la mayor concentración de microinclusiones fluidas en las partes oscuras (Figs. 7a-f). Las formas microesferulíticas presentan un mayor desarrollo en la zona externa (e) y se adentran mínimamente en las zonas de transición ( $t$ ) e interna (i). Por el contrario, es en estas últimas zonas donde se aprecia otra forma de silicificación a escala fina (fine-scale replacement), no fibrosa, que mantiene las láminas de crecimiento originales dibujadas en continuidad con la microestructura carbonatada inicial (Figs. 7a-f). A pesar de esta intensa silicificación que afecta al tubo carbonatado de los ejemplares de $R$. spirulaea recogidos en Punta Galea, este proceso no se ha extendido ni a los bioclastos ni al sedimento-cemento incluido en el lumen de los ejemplares estudiados (Figs. 7a-d).

En el afloramiento de la NA-718, Km 28 de sierra Urbasa (área 2) las silicificaciones también son generalizadas, pero aquí el remplazamiento es algo diferente al anteriormente comentado. La silicificación en forma de microcuarzo $(<20 \mu \mathrm{m})$ parece avanzar a través del sedimento carbonatado (c) que rellena el lumen, conservándose una parte del mismo sin silicificar, pero no así los bioclastos (b) incluidos en él, que quedan afectados. La silicificación más intensa es la que afecta a la capa 2 y parte de la capa $1 *$ (más reciente), predominantemente a las zonas $i^{*}-t^{*}$, donde se conservan en continuidad las líneas de crecimiento silicificadas. El avance queda frenado con un reborde contínuo carbonatado de microesparita $(\mathrm{m})$ ya en la zona $\left(\mathrm{e}^{*}\right)$, prácticamente intacta y con las laminaciones originales bien marcadas (Figs. 8a-h). La completa silicificación del sedimento carbonatado se produce mediante microcuarzo mayoritario y con formas esferulíticas (s) coalescentes de cuarcinalutecita (ver detalle en Fig. 8h*, esferulitos con elongación positiva en $1^{\circ}$ y $3^{\text {er }}$ cuadrante), para avanzar hacia la capa $2 *$ y capa $1 *$ (zonas i*-t*). El reborde carbonatado $(\mathrm{m})$ hace de barrera al avance de la silicificación ya en la zona $\mathrm{e}^{*}$, donde quedan perfectamente conservadas las líneas de crecimiento originales claras y oscuras (Figs. 8c-h).

Por el contrario, cuando la silicificación no se inicia a través del lumen, ya que quedó ocupado por sedimento fino (f) o por una cementación de calcita esparítica (c) no favorable para el proceso, el comportamiento es diferente. Así, en la sección transversal de un ejemplar de morfología troco-planiespiral de la localidad de Anderatz (Figs. 9ab), se reconoce una intensa silicificación, constituida por esferulitos (s) de cuarcina-lutecita que reemplazan completamente a la zona externa (e) de la capa (1) del tubo. Mientras que las zonas i-t quedan minoritariamente afectadas y conservan las laminaciones originales carbonatadas (Figs. 9c-h). La silicificación esferulítica se produce en dos direcciones contrarias $\left(\mathrm{S}_{1}\right.$ y $\left.\mathrm{S}_{2}\right)$ que avanzan hacia la parte central de la zona externa, dejando los rastros de las inclusiones fluidas de tonos oscuros concentradas, bien en el núcleo o en mismo frente del esferulito (Figs. 9g-h). Mediante el MEB, se constata que, en general, la silicificación irregular del lúmen diferencia a la capa (2) por una silicificación completa, que es remarcada por la disolución diferencial, frente a la microestructura interna (1), con pequeñas islas de silicificación (Figs. 10a-b). Por otro lado, el reemplazamiento por esferulitos de cuarcinalutecita parece ser más favorable en los pequeños prismas de la zona (i) que en los más desarrollados de la zona (e) (Figs. 10c-d).

\section{DISCUSIÓN}

\subsection{Modos de vida y estados de conservación}

Desde un punto de vista paleobiológico, en un trabajo anterior los autores del presente estudio llegaron a la concusión, a partir de la propia morfología del tubo, de la localización de ejemplares con la porción planiespiral del tubo bien desarrollada dentro de las margas en posición subvertical con respecto al plano de estratificación, y de la disposición de rellenos y cementos en la cavidad del tubo (lumen), con ejemplos de texturas geopetales, que la posición de vida en la madurez de los individuos de $R$. spirulaea debió de ser vertical dentro del sustrato fangoso (Elorza \& Astibia, 2017). Esta misma idea es sostenida en trabajos anteriores realizados en la península Antártica para varias especies del género Rotularia y Austrorotularia por Macellari (1984), Seilacher et al. (2008) y Seilacher \& Gishlick (2014).

Desde un punto de vista tafonómico existe una notable diferencia en cuanto a los estados mecánicos de conservación de los fósiles estudiados por áreas. Así, aunque en los fósiles de algunos de los afloramientos del área 1 (Cuenca de Pamplona) sean frecuentes las señales superficiales de disolución, los tubos de Rotularia no muestran signos de desgaste ni diferencias composicionales ni texturales entre su relleno sedimentario y la matriz, indicando que se tratarían de elementos conservados por un proceso de acumulación, sin apenas o nula remoción tafonómica (sensu Fernández López, 2000) (Elorza \& Astibia, 2017). No ocurre lo mismo con los fósiles de Rotularia provenientes de las otras dos áreas, incluidos en las calcarenitas de la Formación Urbasa-Andia (área 2) y en las megabrechas de la sucesión turbidítica de Punta Galea (área 3), respectivamente, que corresponderían con toda probabilidad a elementos removilizados (resedimentados y/o reelaborados).

Una característica resaltable de la mayoría de los ejemplares de $R$. spirulaea, presentes en las tres áreas prospectadas, es que están desprovistos de la parte desenrollada del tubo (chimenea) propia del estadio adulto, debido a que este tipo de estructura tiende a fracturase por su base, a causa de los procesos de remoción o de las 

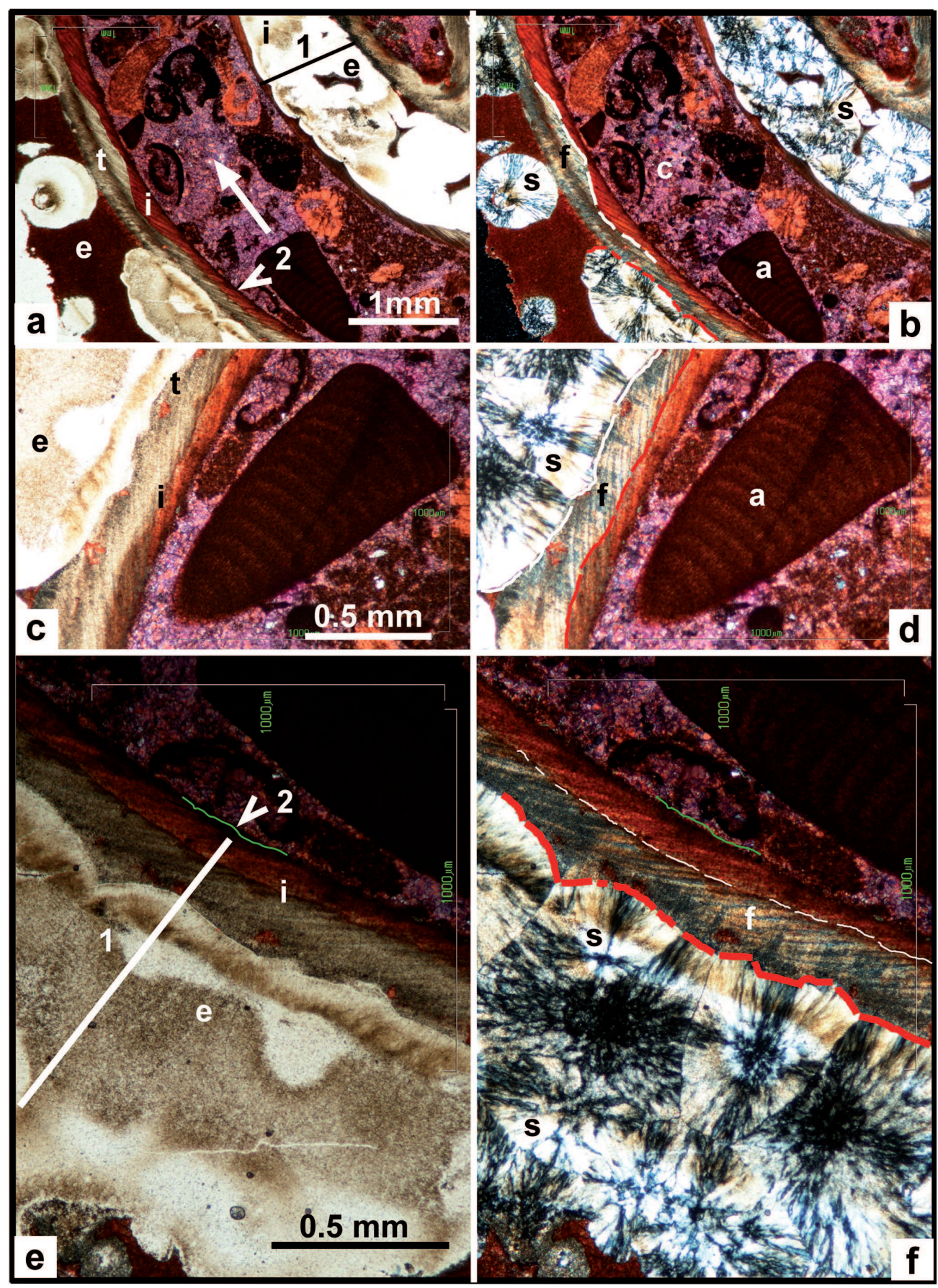

Figura 7. Microestructura del tubo de un ejemplar (RPG.2) de Rotularia spirulaea (Lamarck, 1818) en sección ecuatorial, recogido en el área 3, Punta Galea (Getxo, Bizkaia). a-b) Vista parcial de la sección donde se aprecia la intensa silicificación sufrida en la zona externa (e) con formación de esferulitos de cuarcina-lutecita (s), mientras que las zonas (t-i) de la capa (1), mantenienen las laminaciones por medio de una silicificación fina (f). El relleno del lumen está formado por una mayoría de bioclastos micritizados (algas calcáreas (a), miliólidos, etc.), y cemento (c) de calcita equant. La capa interna (2), no silicificada, es apenas perceptible. c-d). Detalle de las imágenes anteriores, parcialmente giradas, donde se quiere destacar el frente de silicificación por medio de esferulitos (s), señalado por la línea blanca discontinua, para dar paso a la fina silicificación (f), manteniendo las laminaciones, y remarcado su límite con la zona (i) no silicificada por una línea roja discontinua. e-f) Se aprecia con mayor nitidez la silicificación sufrida, formando un frente de esferulitos (s), que contiene a la zona externa (e) y (t), además de parte de la interna (i), con una gran cantidad de microinclusiones fluidas. El límite de este frente queda señalado por la línea roja discontinua. La fina silicificación (f) es limitada, remarcada entre las líneas roja y blanca discontinuas; se produce en la zona (i), manteniendo las laminaciones en continuidad con las de la zona no silicificada, hasta alcanzar el contacto con la capa interna (2), señalada por la línea verde apenas perceptible. Nícoles paralelos (a, c, e) y cruzados (b, d, f). 
presiones litostáticas sufridas durante la compactación del sedimento. Solamente en el área $\mathbf{1}$, y de manera excepcional, quedan conservadas (Figs. 3a-c) e incluso hay posibles señales de readaptaciones ya en vida marcadas por destacadas irregularidades a lo largo del tubo, sin llegar a la fracturación, como es constatable al microscopio (Fig. 3d). Asimismo, las estructuras bioerosivas producidas sobre la concha son excepcionales por su escasez y tan solo se han reconocido las originadas por briozoos (?Pinaceocladichnus isp.) y por gasterópodos (Oichnus isp.) en unos pocos ejemplares de la misma área (Elorza \& Astibia, 2017; fig. 2b, e).

Como ya se ha indicado, los efectos de la silicificación han sido observados exclusivamente en las áreas 2 y 3 y quedan en evidencia en la superficie del tubo mediante los llamados anillos de beekita. A partir de la implantación de varios núcleos individualizados y dispersos se van desarrollando apretadas estructuras de anillos concéntricos, que dejan restos de la microestructura carbonatada sin reemplazar (Figs. 3e-f). Tal como lo hizo notar Holdaway \& Clayton (1982), se constata que estos anillos no son visibles externamente hasta que la meteorización reciente disuelve la fina lámina superficial de microestructura carbonatada, mantenida durante el proceso de silicificación. Ello nos permite indicar que los ejemplares recolectados en estas dos áreas llevan exhumados un tiempo suficientemente largo como para quedar liberados de la roca caja y ser meteorizados por aguas ácidas capaces de disolver esta fina lámina exterior.

\subsection{Fosildiagénesis y rellenos sedimentarios}

\subsubsection{Silicificación}

Dada la alteración diagenética sufrida en las tres áreas estudiadas, no es posible conocer exactamente la composición original del tubo carbonatado, si fue de calcita rica o pobre en $\mathrm{Mg}$ o incluso de aragonito, ahora neomorfizado a calcita. En serpúlidos actuales parece que existen ambas mineralizaciones en una misma microestructura, aunque sin especificar si la calcita es rica o pobre en $\mathrm{Mg}$ (Vinn, 2008). Teniendo en cuenta la aparente facilidad con que se produce la silicificación, es posible que la composición original fuera de calcita pobre en $\mathrm{Mg}$, pues es este mineral el que mejor responde al reemplazamiento por sílice (Butts, 2014). Si hubiera sido de aragonito, la relativamente alta solubilidad del mismo lo hubiera disuelto antes de que actuara la silicificación (Holdaway \& Clayton, 1982), por lo que sin otras evidencias, inicialmente se descarta la presencia de aragonito. Los análisis por DRX indican que se corresponden con una calcita con un 4,2\%$3,9 \%$ de $\mathrm{MgCO}_{3}$, aunque estos análisis han sido efectuados junto con el relleno del cemento carbonatado posterior, lo cual invalida la cuantificación.
El proceso de silicificación parece que está potenciado por una temprana degradación de la materia orgánica, producto de la actividad aeróbica microbiana, ocurrida dentro del material esquelético y donde se crea un microambiente altamente restringido. Ello hace que disminuya el $\mathrm{pH}$, aumente el contenido de $\mathrm{CO}_{2} \mathrm{y}$, consiguientemente, se propicie la disolución de la microestructura de calcita, posiblemente pobre en $\mathrm{Mg}$ (Jacka, 1974; Schmitt \& Boyd, 1981; Holdaway \& Clayton, 1982; Cherns \& Wright, 2000; Butts, 2014). En estudios experimentales se constata que la silicificación de microbios (Amores \& Warren, 2007) y de material esquelético (Paraguassu, 1976; Butts et al., 2011) ocurre cuando se mantiene el fluido intersticial saturado en sílice y en condiciones ácidas a baja temperatura. Estos procesos pueden producir sesgos tafonómicos (Butts, 2014).

Resulta remarcable la semejanza morfológica de los anillos de beekita con los patrones cambiantes circulares y espirales de la reacción de Belousov-Zhabotinsky (reacciones BZ); un tipo de reacción redox que no alcanza el equilibrio termodinámico, prototipo de reacción química oscilante (chemically-oscillating reaction), ejemplo del comportamiento de un sistema químico caótico (Winfree, 1984). Papineau et al. (2017) mencionan patrones fractales semejantes en gránulos con fósiles de microorganismos en cherts estromatolíticos del Paleoproterozoico del área del Lago superior (Norteamérica) y concluyen que la oxidación diagenética de materia orgánica a través de reacciones químicas oscilantes contribuyó a la formación de estos esferoides sedimentarios. Asímismo, Dodd et al. (2018) fundamentan que la génesis de las formaciones de hierro granular (Granular Iron Formations, GIFs) depositadas en las plataformas continentales de finales del Paleoproterozoico implican actividad microbiana y reacciones químicas oscilantes, de ahí el potencial de estos gránulos como bioseñales en los estudios de bioquímica del Precámbrico y en Astrobiología.

En nuestro caso, la mayor parte de la silicificación que se produce en las rotularias pertenecientes al área 3 (Punta Galea), se localiza en la bien desarrollada zona externa (e) de la capa (1), con la presencia de sílice fibrosa en forma esferulitos de cuarcina-lutecita (s). Ello nos permite confirmar la vigencia de este modelo morfológico de silicificación por núcleos dispersos y las formas de avance por crecimiento concéntrico producidas durante el desarrollo de los esferulitos $\left(\mathrm{S}_{1}\right.$ y $\left.\mathrm{S}_{2}\right)$, a ambos lados de las paredes del lumen (Figs. 3g-h). En menor medida, la silicificación puede alcanzar a la zona de transición $(\mathrm{t}) \mathrm{y}$ zona interna (i) en forma de un reemplazamiento a escala fina (f), aunque conservando las líneas de crecimiento originales (Figs. 6a-f; 7a-f). La presencia de una u otra morfología de reemplazamiento puede deberse al control que ejerce la tasa relativa del aporte de sílice frente a la disolución de carbonato, puesto que a menor tamaño de grano queda una mayor superficie del cristal expuesta al ataque. 


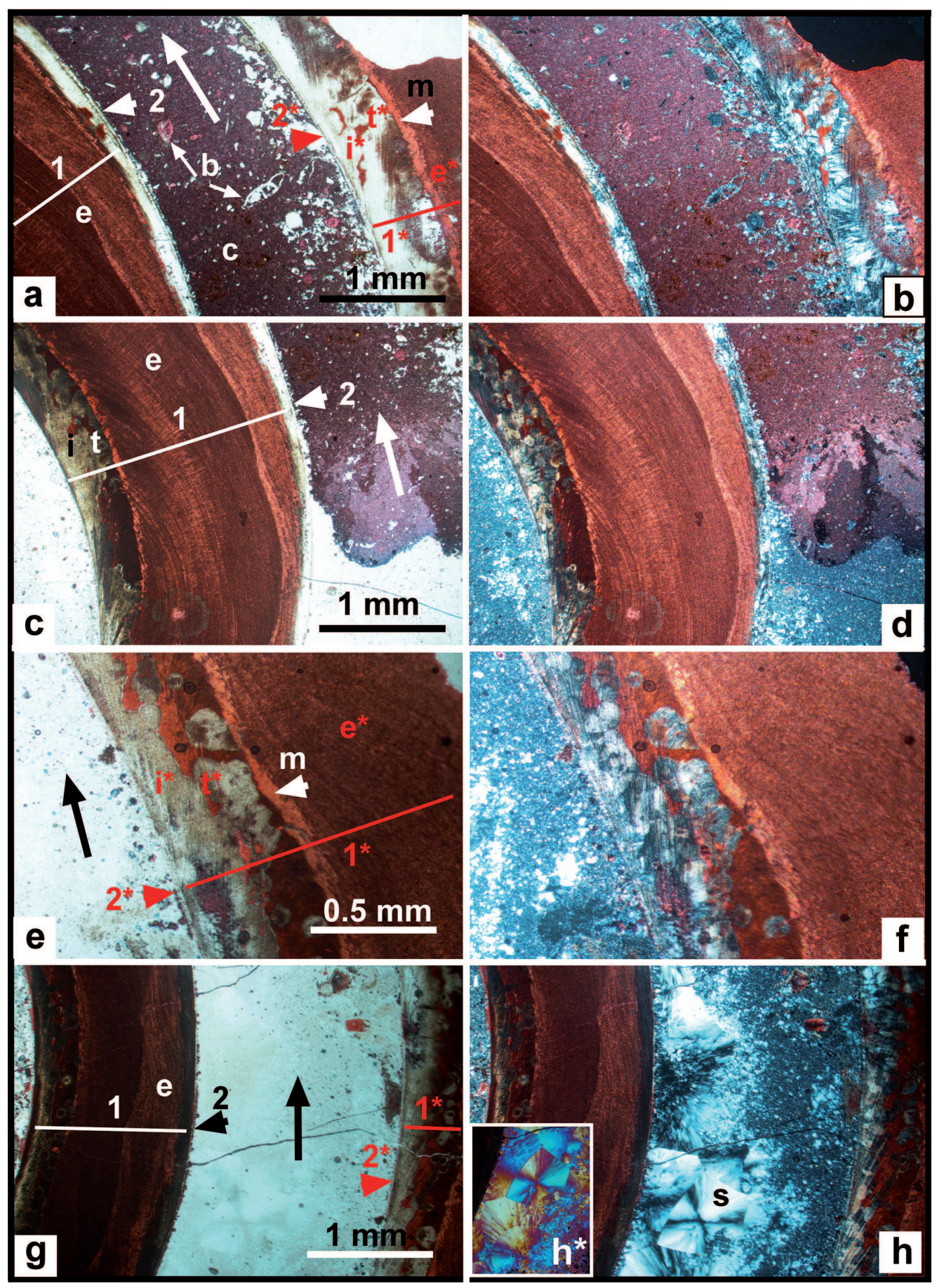

Figura 8. Microestructura del tubo de un ejemplar (CRG.8) de Rotularia spirulaea (Lamarck, 1818), en sección ecuatorial, proveniente del afloramiento del Km 28 de la carretera NA-718, Urbasa, Fm. Urbasa-Andia, del área 2. a-d) Aspecto general de la capa externa (1) anterior frente a la capa externa $\left(1^{*}\right)$, menos gruesa, donde han quedado silicificadas las zonas (i* y $\left.t^{*}\right)$ en parte conservando las líneas de crecimiento hasta apenas alcanzar la zona ( $\left.\mathrm{e}^{*}\right)$, frenada por un reborde carbonatado de calcita esparítica $(\mathrm{m})$. La silicificación en esta parte de la espira es más extensa que en la anterior. La capa interna (2) está completamente silicificada a ambos lados del lumen. El lumen está ocupado por sedimento-cemento carbonatado microcristalino (c) con bioclastos (b) silicificados. La silicificación puede afectar a la totalidad del lumen (c-d). Las flechas blancas indican el sentido de enrollamiento de la espira. e-f) Detalles de las capas ( $1^{*}$ y $\left.2^{*}\right)$ parcialmente silicificadas, donde se aprecia las zonas $\mathrm{i}^{*}, \mathrm{t}^{*} \mathrm{y} \mathrm{e}^{*}$, además del reborde carbonatado $(\mathrm{m})$. La silicificación afecta al relleno del lumen y avanza hacia el tubo conservando parcialmente las laminaciones originales. La flecha negra indica el sentido de enrollamiento de la espira. g-h) Vistas de la completa silicificación del relleno del lumen por cuarzo microcristalino y por esferulitos (s) de cuarcina-lutecita, con detalle de su elengación en la parte inferior izquierda (h*). Las vueltas de espira permiten observar una silicificación prácticamente inexistente de la capa (1) en la vuelta anterior, frente al mayor desarrollo en las capas ( $1^{*}$ y 2*) más recientes. Nícoles paralelos (a, c, e, g); nícoles cruzados $(\mathbf{b}, \mathbf{d}, \mathbf{f}, \mathbf{h})$. 


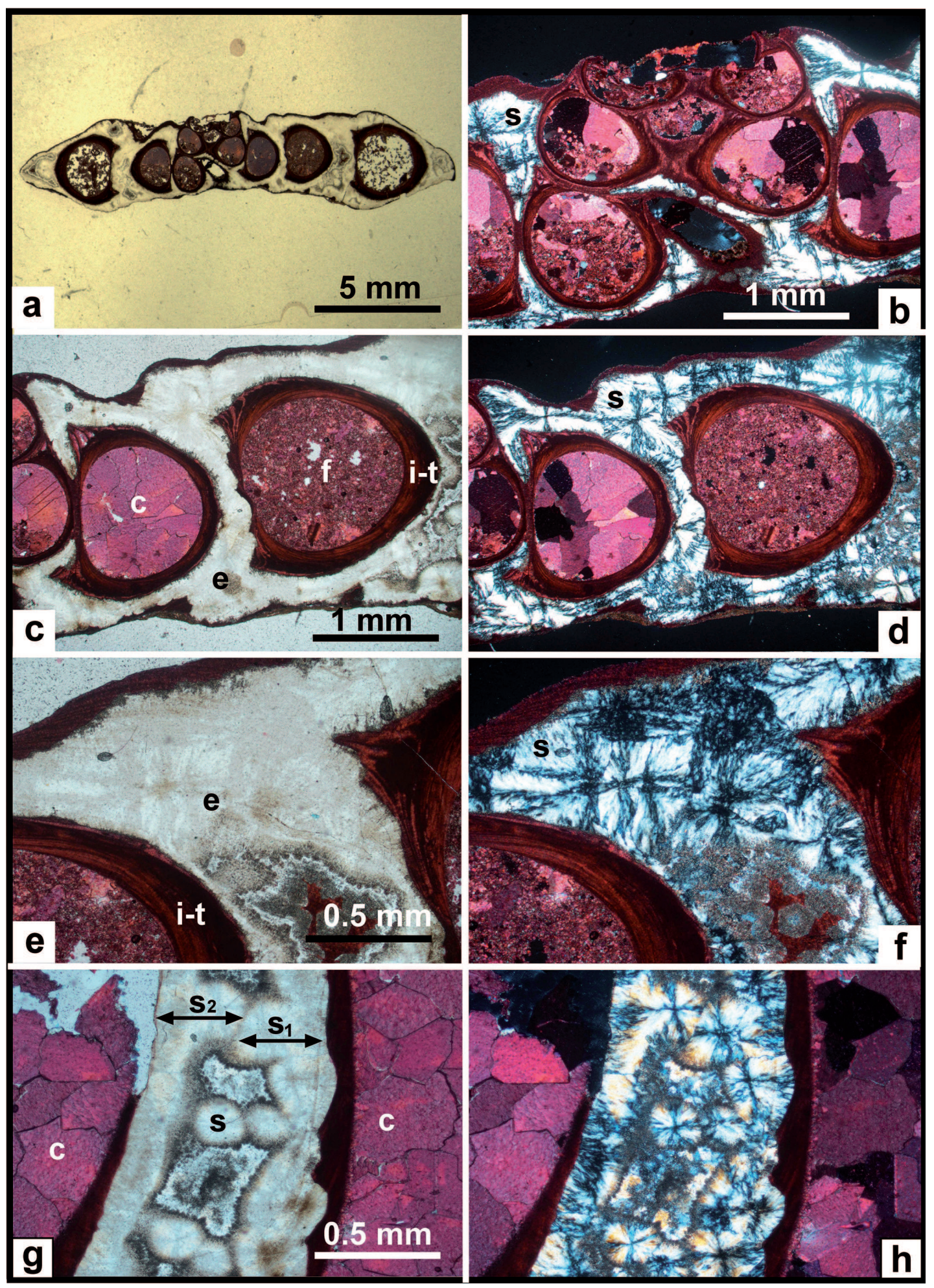

Figura 9. Microestructura del tubo de un ejemplar (CRG.9) de Rotularia spirulaea (Lamarck, 1818), en sección transversal, recogido en Anderatz, Fm. Urbasa-Andia, del área 2 (Arderatz y sierra de Urbasa, Navarra). a) Vista general del ejemplar donde se aprecia un primer estadio trocoespiral y otro posterior planiespiral. b) Aspecto de la zona central, con nícoles cruzados, donde la silicificación ocupa gran parte de la microestructura del tubo. Contrariamente, el relleno del lumen se produce por sedimento y cemento carbonatado. c-f) Vistas y detalle de la casi completa silicificación por esferulitos (s) de cuarcinalutecita afectando a la zona interna (i) más desarrollada de la capa externa (1). Se mantienen sin silicificar las zonas (i-t) y la capa interna (2), mientras que el lumen es rellenado por sedimento fino (f) y cemento espático (c), teñido en rojo. g-h) Detalles en sección ecuatorial del ejemplar (CRG.10), recogido en el mismo enclave de Arderatz. La silicificación, por medio de esferulitos (s) de cuarcina-lutecita, despliega dos frentes contrapuestos con acumulación de inclusiones fluidas sin ordenamiento en algunos núcleos y en la periferia $\left(\mathrm{S}_{1}\right.$ y $\left.\mathrm{S}_{2}\right)$. Nícoles paralelos $(\mathbf{c}, \mathbf{e}, \mathbf{g})$; nícoles cruzados $(\mathbf{d}, \mathbf{f}, \mathbf{h})$. 
En general, un reemplazamiento a escala fina (f) permitiría conservar las líneas de crecimiento de la concha, y se produciría cuando la aportación de sílice es abundante. Por otro lado, una morfología de anillos concéntricos de beekita sería viable cuando la disponibilidad es limitada. Por último, la formación de una corteza granular blanca silícea se realizaría cuando la disolución del carbonato fuera restringida (Holdaway \& Clayton, 1982).

En las rotularias estudiadas, la pérdida del trazado de las líneas de crecimiento blancas y oscuras propias del tubo carbonatado se origina durante la formación de los esferulitos de cuarcina-lutecita, concentrándose las microinclusiones fluidas de tonos oscuros sin aparente estructuración, bien en su núcleo o en los frentes de avance de los mismos (Figs. 6-7). Esta concentración de microinclusiones parece que es debido a un proceso de exolución de aguas atrapadas en los minerales semi-hidratados de la sílice (opalo-CT precursor?) durante la formación de los microesferulitos en la zona externa (e). Si la disponibilidad de sílice es mayor, el frente de avance hacia la zona de transición (t) e interna (i) produce un fino reemplazamiento (f) y las líneas de crecimiento blancas y oscuras se conservan, tal como se puede apreciar con un aumento mayor en las Figuras 7a-f. Puede entenderse que aquí el micro- megacuarzo, formado con una mayor concentración de sílice, es la primera variedad que se produce en la vanguardia del frente de avance, posteriormente seguido de los esferulitos de cuarcina-lutecita fibrosa. Ello permite asegurar que la silicificación se realiza por remplazamiento sin destrucción de las microestructuras originales, y queda descartada la posibilidad de permineralización en los espacios vacios. En resumen, puede sugerirse que los fluidos ya ricos en sílice han migrado a través del relleno del lúmen, pobre en materia orgánica y no favorable para la silicificación, hasta encontrar las paredes del tubo, con material esquelético rico en materia orgánica, favorable para el reemplazamiento temprano por la sílice de la forma indicada más arriba.

En nuestra opinión, la fuente de la sílice es biogénica, dado la ausencia en la columna litostática de materiales con un suficiente componente silicatado capaces de alterarse diagenéticamente y aportar la necesaria cantidad de sílice a los fluidos del sedimento. Tampoco parece factible un aporte directo de sílice por actividad hidrotermal en la cuenca, ya que no hay eventos próximos de importancia. Por el contrario, en la colección Ruiz de Gaona se conservan varios fósiles de esponjas silicificados de los afloramientos de los kms 23-24 y 24-25 de la NA-718 (área 2), localidades de donde provienen muchos de los fósiles de Rotularia aquí estudiados. La ausencia de silicificación en los serpúlidos del área 1 de la cuenca de Pamplona es posible que pueda explicarse por el hecho de que aunque en la sección de Ardanatz (AD) los fósiles de esponjas hexactinélidas y litisteidas son localmente muy abundantes (Astibia et al., 2014, 2016), estos se ubican mayoritariamente en la parte baja de la serie y no en la media y alta, donde son abundantes los fósiles de Rotularia. Por otro lado, en la sección del Valle de Itzagaondoa (IV), donde los fósiles de estos serpúlidos son muy abundantes, no hay localizado hasta la fecha ningún fósil de esponja. Otro hecho que podría explicar la ausencia de silicificaciones en el área $\mathbf{1}$ sería la naturaleza margosa, poco porosa, que dificultaría, la movilidad de los fluidos intersticiales en el cuerpo sedimentario, a diferencia de lo que ocurriría en los niveles calcareníticos y megabrechas de las otras áreas de estudio. La composición opalina de las esponjas facilita una mayor disolución con la incorporación de sílice a los fluidos intersticiales, puesto que la solubilidad de la sílice amorfa en los caparazones de los microorganismos (210 ppm a un $\mathrm{pH}<9$ y a $25^{\circ} \mathrm{C}$ ) permite una mayor disolución que el cuarzo en general ( $6 \mathrm{ppm}$ a un $\mathrm{pH}<9$ a $25^{\circ} \mathrm{C}$ ) (Krauskopf, 1979).

Una vez que el sedimento ha sido removilizado de su posición original, los fluidos intersticiales ya ricos en sílice pueden desplazarse con facilidad por el sedimento poco compactado con una fuerte porosidad y permeabilidad inicial. Esta facilidad en el movimiento de los fluidos dentro de los materiales resedimentados (áreas 2 y 3), contrasta con la falta de movilidad en el área correspondiente a la Formación Margas de Illundain.

En las rotularias afectadas por la silicificación del área $\mathbf{2}$ se observa una variación con respecto al comportamiento de las del área 3. En el área 2 (Km 28), hay ejemplares donde se aprecia cómo el sedimento que rellena al lumen queda silicificado mayoritariamente por microcuarzo e incluso por esferulitos de cuarcina-lutecita (Fig. 8a-h*). El avance se produce en dos frentes a ambos lados del lumen, siendo discreto en la parte casi imperceptible de la capa (2) y en la zona externa (e) más antigua de la vuelta anterior, mientras que a partir del contacto de la capa $2^{*}$ queda afectada intensamente tanto la zona interna $\left(i^{*}\right)$ como la de transición $\left(\mathrm{t}^{*}\right)$, pertenecientes a la capa $\left(1^{*}\right)$ de la nueva vuelta de espira (Figs. 8e-h). La silicificación en la microestructura orgánica conserva las líneas de crecimiento y el límite del avance se produce con la formación de un pequeño reborde carbonatado de calcita esparítica (m), quedando las zonas externas (e y e*) mucho más gruesas, sin ningún signo de silicificación (Figs. 8e-f). Esto puede ser interpretado como que ante un aporte limitado de sílice, gran parte de la misma sería la responsable de la silicificación del sedimento del lumen, siendo la sobrante la que reemplazaría la microestructura del tubo más reciente (¿son más ricas en materia orgánica las capas $2 *$ y $1 * ?$ ). Otra parte de la sílice afectó minoritariamente a las capas (2 y 1) de la vuelta anterior donde, al contactar con el medio marino durante un tiempo la superficie de la capa (1), pudo haber una modificación del contenido en materia orgánica y por tanto ser menos favorable para su reemplazamiento.

El comportamiento es diferente cuando el lumen está ocupado por sedimento fino carbonatado y/o cemento espático sin evidencias de silicificación, puesto que el 


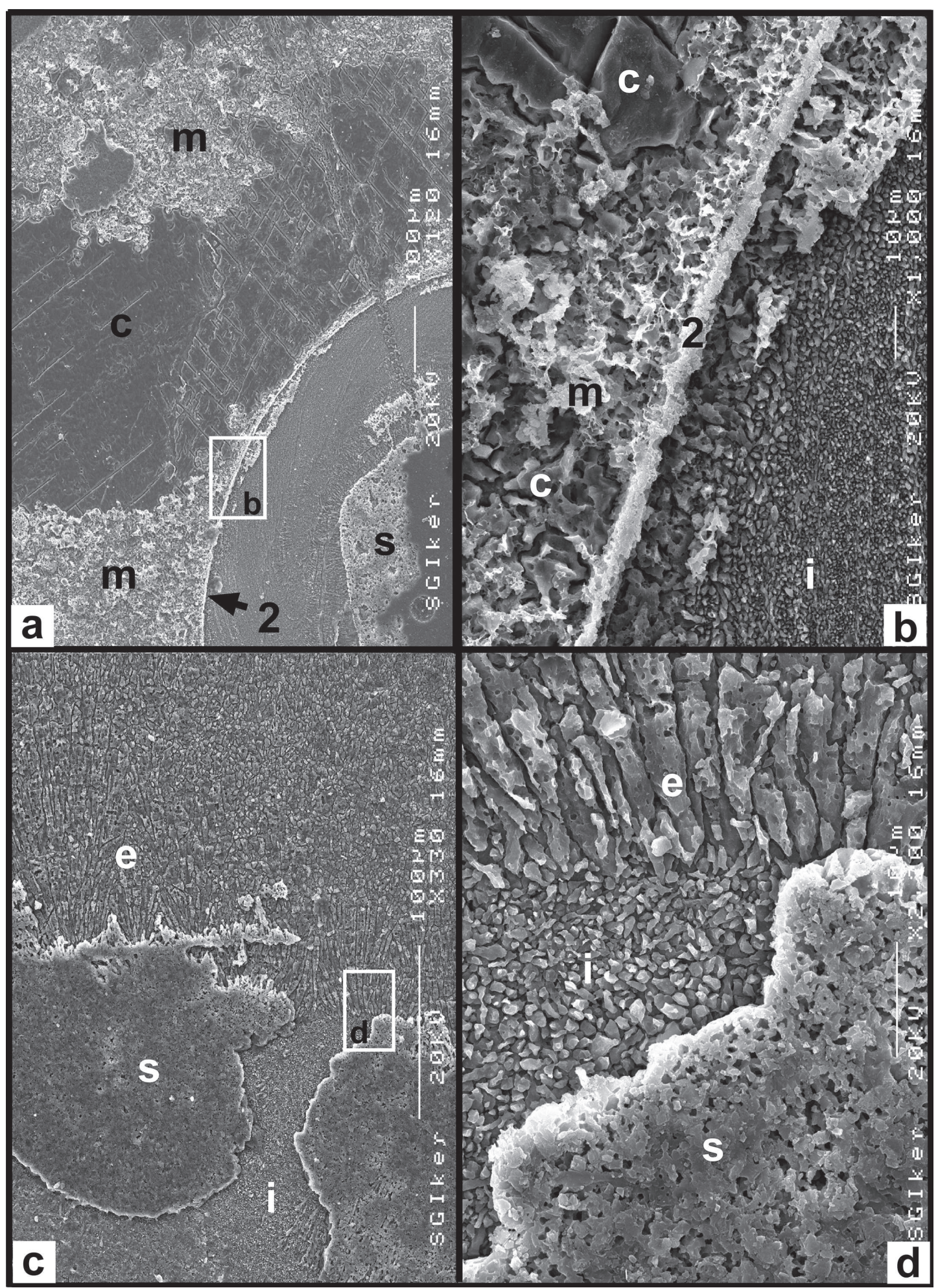

Figura 10. Vista general y de detalle mediante el MEB de la microestructura del tubo de un ejemplar en corte ecuatorial de Rotularia spirulaea (CRG.8), proveniente del afloramiento del Km 28 de la carretera NA 718, Urbasa, Fm. Urbasa-Andia, del área 2. a) Aspecto general donde se aprecia la cementación parcial del lumen por grandes cristales de calcita esparítica (c), además de estar parcialmente silicificado por cuarzo microcristalino (m). En la microestructura del tubo es reconocible la capa (2), completamente silicificada. b) Detalle de la Fig. (10a), donde se constata la silicificación (m) y relleno por cemento (c) en el lumen frente a la delgada capa (2) silicificada y los inicios de la zona interna (i) de la capa (1), formada por cristales carbonatados muy pequeños. c) Aspecto general de la silicificación (s) en botones de cuarcina-lutecita reemplazando selectivamente a la zona (i), sin alcanzar la zona (e), ambas perteneciente a la capa (1). d) Detalle de la foto anterior, en el que se aprecian las silicificación (s) en contacto y remplazando la zona (i), en la frontera con la zona (e), donde puede observarse el mayor desarrollo de los cristales prismáticos. La muestra ha sido atacada con $\mathrm{HCl}$ diluido (5\%) durante 1 minuto. 
inicio y avance de la misma no se produce desde el interior del lumen. Así, en un ejemplar de Anderatz (CRG-9), la zona externa de la capa (1) queda completamente silicificada por numerosos esferulitos de cuarcina-lutecita (s), mientras que las zonas de transición (t) e interna (i) quedan afectadas en menor medida e incluso intactas (Figs. 9a-h). Resulta visible cómo desde la zona externa (e) se producen dos frentes de avance opuestos en dirección $\left(\mathrm{S}_{1}\right.$ y $\mathrm{S}_{2}$ ), para la formación de los esferulitos como puede apreciarse en las Figuras 9g-h.

Con los ejemplares recogidos en el área 2 (Sierra Urbasa-Andia), puede sugerirse que la silicifición es por reemplazamiento y nunca por permineralización, que avanza desde el remplazamiento a escala fina hacia los anillos de beekita en función de la disponibilidad de la sílice, y que afecta tanto a la capa (2) como a la capa (1). También parece verosimil que un mayor contenido orgánico, tanto en el sedimento como en las microestructuras carbonatadas, propicie una selectiva polaridad del reemplazamiento en las diferentes zonas comentadas (Figs. 7-9). Cuando el lumen está ocupado por sedimento y/o cemento carbonatado no afectado, la silicificación en el tubo parece que puede infiltrase desde la zona externa (e) de la capa (1) (Fig. 9).

\subsubsection{Rellenos sedimentarios y cementos}

En la mayoría de los ejemplares del área 1 (Cuenca de Pamplona), estudiados en lámina delgada, se reconoce un relleno parcial del lumen por un fino sedimento siliciclástico, con un alto componente carbonatado de cristales de micrita-microesparita (Fig. 4a). Los terrígenos, más visibles por su mayor tamaño $(<50 \mu \mathrm{m})$, son cristales de cuarzo (confirmado por DRX), redondeados sin llegar a estar grano-soportados, y sin marcar laminaciones. Ocasionalmente se puede observar una mayor concentración en la abertura que pudiera taponar la misma, remarcada con una cementación más intensa justo en el contacto inferior con la calcita en mosaico (equant) (Fig. 4c) (para un mayor detalle ver Elorza \& Astibia, 2017).

Por otra parte en el área 3 (Punta Galea), se reconoce un relleno completo del lumen formado por un alto componente de conchas de foraminíferos (Globigerinida, Miliolida y otros) y fragmentos de algas calcáreas, junto con otros bioclastos de difícil identificación debido a la intensa micritización sufrida. La presencia de terrígenos es mínima y solamente se encuentran en las vueltas internas del lumen, mientras que el cemento está ampliamente representado con grandes cristales de calcita en mosaico $(100 \mu \mathrm{m})$ que pasan a esparítica (sparry) $(300 \mu \mathrm{m})$, y que responden a la tinción con tonos violetas indicativos de calcita ferrosa, contrariamente a la tinción roja intensa de los bioclastos formados por calcita no ferrosa (Figs. 6 y 7).

En un ejemplar de Anderatz (área 2), un sedimento fino y cemento carbonatado rellena el lumen del fósil sin evidencia alguna de silicificación frente a la intensa silicificación del tubo carbonatado (Fig. 9a-h). En los afloramientos de la sierra de Urbasa de la misma área (NA-718, km 25), como ya se ha indicado, la mayoría de los ejemplares seccionados no presentan el lumen relleno. Posiblemente el relleno carbonatado haya sido disuelto y su lugar ocupado por material perteneciente al suelo actual, que se pierde al seccionar el tubo (Figs. 3gh). Contrariamente, en ejemplares del km 28 (NA-718), se produce un relleno carbonatado y se aprecia el aporte de pequeñas conchas de foraminíferos, parcialmente silicificadas, además de un sedimento de grano fino-medio, todo ello cementado por grandes cristales de calcita en mosaico-esparítica (equant-sparry). Ocasionalmente, el sedimento de grano fino-medio ha sido silicificado con microcristales de cuarzo y formas esferulíticas de cuarcinalutecita (Figs. 8a-h*).

El estudio del relleno sedimentario y los cementos carbonatados mediante catodoluminiscencia (CL) en ejemplares del área 1, nos aporta la visión de que el relleno aloquímico tiene un alto contenido en carbonato y resulta de luminiscencia limitada en tonos rojos no intensos, mientras que algunos cristales de cuarzo detrítico, incluidos en él, se reconocen por la coloración azulada. Respecto a los cementos carbonatados su comportamiento mayoritario es apenas luminiscente (dull) o incluso no luminiscente, tanto los delgados cristales tempranos aciculares y circungranulares como los considerados radiaxiales, sin que se produzca zonación alguna. Por último, ocupando espacios centrales en las secciones del lumen aparecen cristales de calcita en mosaico con una luminiscencia amarilla intensa, indicativa del estadio final de cementación, solamente reconocidos por su comportamiento luminiscente diferente, al quedar agotado el hierro inhibidor en un sistema ya cerrado (Figs. 11a-b).

También se reconoce una mayor o menor intensidad en la luminiscencia, indicativa de la diagenesis sufrida, entre las capas y zonas de la microestructura del tubo. En la capa 1, la parte más luminiscente corresponde a la zona interna (i) y la zona de transición (t), frente a la zona externa (e) menos luminiscente (Figs. 11c-d). Se pueden justificar estas diferencias porque las zonas (i-t) presentan un tamaño de grano notablemente inferior al de la zona (e), y por tanto son más susceptibles a ser atacadas por los fluidos diagenéticos intercambiadores de cationes. Además, la zona $(t)$, con mayor cantidad de materia orgánica propicia la descomposición de la misma, aumentando la porosidad y la instalacion de cementos luminiscentes procedentes de los fluidos diagenéticos.

En relación a los ejemplares de las áreas $\mathbf{2}$ y $\mathbf{3}$, se aprecia que la silicificación en ambas morfologías (remplazamiento a escala fina y anillos de beekita) no produce luminiscencia, mientras que se genera una intensa homogenización en rojo en todas las zonas (e-t-i) de la capa (1), sin poder apuntar alguna diferencia relevante entre ellas (Figs. 11e-h). 


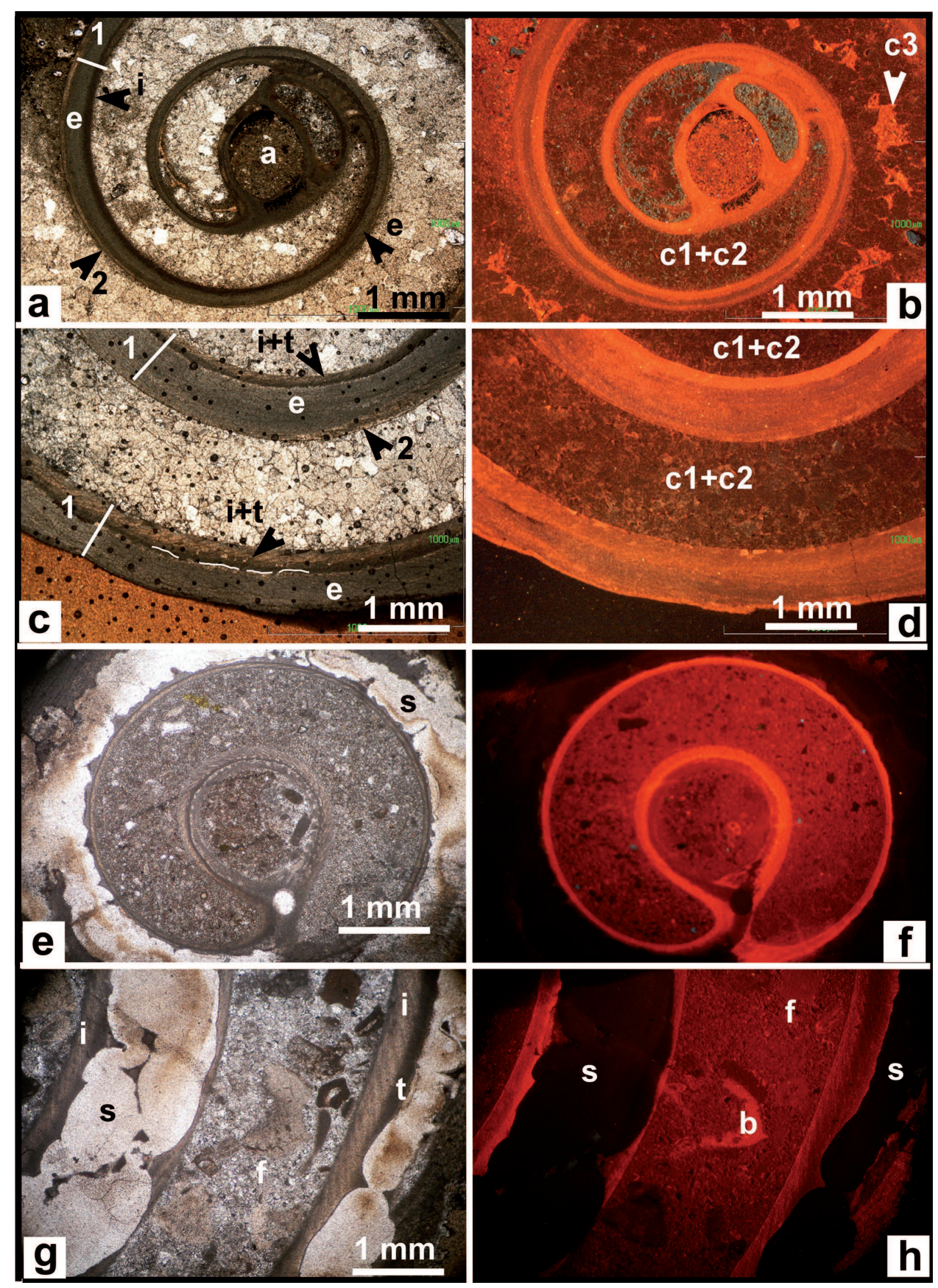

Figura 11. Reconocimiento del comportamiento mediante catodoluminiscencia (CL) de las diferentes microestructuras y el relleno del tubo de dos ejemplares (IV.51 y IV.52) de Rotularia spirulaea (Lamarck, 1818) del área 1, sección de Itzagaondoa, Fm. Margas de Ilundain (Cuenca de Pamplona, Navarra) y de un ejemplar RPG.1 del área 3, (Punta Galea, Bizkaia). a) Sección ecuatorial de IV.51 en la zona central de anclaje (a) y las microestructuras interna (i) y externa (e) pertenecientes a la capa externa (1). Es visible también la apenas perceptible capa interna (2). Nícoles paralelos. b) Vista en CL, donde se aprecia la diferencia de luminiscencia entre la zona interna (i) y la zona externa (e), además de la falta de la misma en el cemento esparítico $(\mathrm{c} 1+\mathrm{c} 2)$, salvo el último estadio (c3) luminiscente. c) Detalle de las dos últimas vueltas de espira de IV.52, donde se observa la capa (1), con la zona interna asociada a la zona de transición (i+t) y externa (e), además de los cementos indiferenciados. Nícoles paralelos. d) Vista en CL, donde la $(\mathrm{i}+\mathrm{t})$ unidas son más luminiscentes que la $(\mathrm{e})$. Los cementos $(\mathrm{c} 1+\mathrm{c} 2)$ son apenas luminiscentes. e) Vista en sección ecuatorial del ejemplar RPG.1, con la zona central de anclaje rellena de sedimento y las microestructuras del tubo ampliamente silicificadas (s) (nícoles paralelos). f) Vista en CL del sedimento ligeramente luminiscente, mientras que los restos de la microestructura son luminiscentes en rojo intenso, permaneciendo no luminiscente la parte silicificada. g) Vista a mayor detalle de la microestructura silicificada (s) y restos no afectados de la zona interna (i) laminada y parte de la zona (t) oscura. El relleno carbonatado no está silicificado (nícoles paralelos). h) Vista en CL, en la que destaca una mayor luminiscencia en la microestructura no afectada por silicificación, el relleno (f) ligeramente luminiscente (con un bioclasto b, más luminiscente) y la zona silicificada (s) no luminiscente. 


\section{CONCLUSIONES}

Los tubos del anélido fósil Rotularia spirulaea (Lamarck, 1818) del área 1 (Cuenca de Pamplona, sinclinal de Aranguren-Itzaga, Navarra), abundantes en la transición entre las formaciones Areniscas de Ardanatz y Margas de Ilundain y en la parte alta de la segunda de estas formaciones (Bartoniense y (?) Priaboniense), se consideran respecto a su estado de conservación como elementos acumulados en el sedimento y presentan un menor grado de modificación tafonómica que los fósiles de las otras dos áreas de estudio 2 (Anderatz y sierra de Urbasa, Navarra) y 3 (Punta Galea, Bizkaia), resultando, por tanto, más adecuados para el estudio paleobiológico de sus estructuras esqueléticas.

La composición de las mismas es calcítica, sin evidencia de aragonito. Se confirma que la microestructura del tubo está constituida por dos capas: una externa (1), de grosor creciente siguiendo el enrollamiento, compuesta por tres zonas en continuidad entre ellas: una primera interna (i) con una microestructura de cristales muy pequeños, tendentes a ser prismáticos, remarcados por las líneas de crecimiento. La zona interna es seguida de una zona oscura de transición (t), flexionada; $y$, finalmente, una zona externa (e), con una estructura prismática de mayores dimensiones, con tendencia a esferulítica y disposición de las líneas de crecimiento en sentido opuesto a las líneas de la zona interna (i). Delimitando al lumen se dispone una capa interna (2), de extrema delgadez $(20-50 \mu \mathrm{m})$, prácticamente imperceptible. La cavidad del tubo (lumen) está habitualmente rellenada por sedimento y/o cementada por grandes cristales de calcita.

En las áreas 2 y 3 los ejemplares de $R$. spirulaea han sufrido remoción tafonómica y también una intensa silicificación selectiva durante la diagénesis temprana, que afecta fundamentalmente a la capa (1). Las formas generadas por reemplazamiento son mayoritariamente microesferulitos de cuarcina-lutecita, que obliteran la microestructura laminar inicial de la zona externa (e), más desarrollada. Minoritariamente se producen cristales de micro-megacuarzo que dibujan un fino remplazamiento (f), con preservación de las laminaciones iniciales en las zonas de transición (t) y en la zona interna (i). El lumen es rellenado con restos de microfósiles (foraminíferos, algas calcáreas), sedimento detrítico (cuarzo-feldespático) y cementado por cristales de calcita en mosaico y esparítica que responden ante la catodoluminiscencia de diferente manera según la procedencia de los ejemplares.

El estudio microestructural de $R$. spirulaea sugiere que el condicionante prioritario para que se produzca la silicificación selectiva, siempre y cuando haya suficiente cantidad de sílice, sería el contenido en materia orgánica que encierra la microestructura. Cuando la disponibilidad de la sílice resultase limitada, el remplazamiento se produciría prioritariamente en las zonas (i), donde el tamaño de grano inicial es sustancialmente menor, quedando los grandes cristales de la zona externa (e) sin ser efectados.

\section{AGRADECIMIENTOS}

A los doctores Eduardo Mayoral (Universidad de Huelva) y Julio Aguirre (Universidad de Granada), revisores de este trabajo. Sus valiosos comentarios han permitido mejorar apreciablemente el manuscrito. Este trabajo ha sido subvencionado, en parte, por el proyecto CGL2013-47521-P (Ministerio de Economía y Competitividad, Servicio de Estado de Investigación, Desarrollo e Innovación, MINECO, Gobierno de España), el Fondo Europeo de Desarrollo Regional (ERDF/FEDER), los grupos de investigación IT1044-16 (Eusko Jaurlaritza/ Gobierno Vasco), PPG17/05 (Universidad del País Vasco/Euskal Herriko Unibertsitatea) y la Fundación Elorza. Los autores agradecen al Dr. Jesús Sesma y Rubén Jiménez de los Fondos de Arqueología del Departamento de Cultura, Deporte y Juventud (Sección de Arqueología, Servicio de Patrimonio Histórico) del Gobierno de Navarra, por sus facilidades y gestiones que han posibilitado estudiar los materiales fósiles de la Colección Ruiz de Gaona. Al Dr. A. Payros (UPV/EHU) por la amable cesión de algunas imágenes (Figs. 1a, 2b) y el apoyo técnico y humano de los SGIker de la UPV/EHU.

\section{REFERENCIAS}

Abad, A. 2001. Paleotaxodonta y Pteriomorphia del Eoceno del Margen Sur de la Depresión Catalana. Tesis Doctoral, Universitat Autònoma de Barcelona, Barcelona (inédita), 803 p. http://ddd.uab.cat/record/37045.

Accorsi Benini, C., Marega, G. \& Ungaro, S. 1992. Analisi paleosinecologica del livello a Rotularia spirulaea di Grancona (Monti Berici, Vicenza). Memorie di Scienze Geologiche, 64, 87-107.

Amores, D.R. \& Warren, L.A. 2007. Identifying when microbes biosilicify: The interconnected requirements of acidic $\mathrm{pH}$, colloidal $\mathrm{SiO}_{2}$ and exposed microbial surface. Chemical Geology, 240, 298-312; doi: 10.1016/j. chemgeo.2007.02.016.

Arbey, F. 1980. Les formes de la silice et l'identication des évaporites en les formations silicifiées. Bulletin Centres de Recherches Exploration-Production Elf-Aquitaine, 4, 309-365.

Astibia, H., Elorza, J., Pisera, A., Álvarez-Pérez, G., Payros, A. \& Ortiz, S. 2014. Sponges and corals from the Middle Eocene (Bartonian) marly formations of the Pamplona Basin (Navarre, western Pyrenees): taphonomy, taxonomy, and paleoenvironments. Facies, 60, 91-110; doi: 10.1007/ s10347-013-0364-2.

Astibia, H., Payros, A., Pereda Suberbiola, X., Elorza, J., Berreteaga, A., Etxebarria, N., Badiola, A. \& Tosquella, J. 2005. Sedimentology and taphonomy of sirenian remains from the Middle Eocene of the Pamplona Basin (Navarre, western Pyrenees). Facies, 50, 463-475; doi: 10.1007/ s10347-004-0026-5. 
Astibia, H., Payros, A., Ortiz, S., Elorza, J., Álvarez-Pérez, G., Badiola, A., Bardet, N., Berreteaga, A., Bitner, M.A., Calzada, S., Corral, J.C., Díaz-Martínez, I., Merle, D., Pacaud, J.M., Pereda-Suberbiola, X., Pisera, A., Rodríguez-Tovar, F.J. \& Tosquella, J. 2016. Fossil associations from the middle and upper Eocene strata of the Pamplona Basin and surrounding areas (Navarre, western Pyrenees). Journal of Iberian Geology, 42, 7-28; doi: 10.5209/rev_JIGE.2016.v42.n1.51601.

Astibia, H., Merle, D., Pacaud, J.M., Elorza, J. \& Payros, A. 2018. Gastropods and bivalves from the Eocene marly formations of the Pamplona Basin and surrounding areas (Navarre, western Pyrenees). Geodiversitas, 40, 211-257; doi: 10.5252/geodiversitas2018v40a11.

Ball, H.W. 1960. Upper Cretaceous Decapoda and Serpulidae from James Ross Island, Graham Land. Falkland Islands Dependencies Survey, Scientific Reports, 24, 1-30.

Barnolas, A., Payros, A., Samso, J.M., Serra-Kiel, J. \& Tosquella, J. 2004. La Cuenca surpirenaica desde el Ilerdiense medio al Priaboniense. In: Geología de España (ed. Vera, J.A.). Instituto Geológico y Minero de España, Sociedad Geológica de España, Madrid, 313-320.

Bouillé, R. de 1873. Paléontologie de Biarritz et de quelques autres localités des Basses Pyrénées. Memoires de la Première Section, Congrès Scientifique de France, 39 Session 1, Pau, 427-468.

Bouillé, R. de 1876. Paléontologie de Biarritz et de Quelques Autres Localités des Basses-Pyrenées. Imprimerie et Lithographie Veronese, Pau, 71 p.

Butts, S.H. 2014. Reading and writing of the fossil record: preservational pathways to exceptional fossilization. In : The Paleontological Society Papers, Volume 20, M (eds Laflamme, J., Schiffbauer, D. \& Darroch, S.A.F.), The Paleontological Society Short Course, October 18, 2014.

Butts, S.H., Krause, Jr.R.A. \& Briggs, D.E.G. 2011. Experimental silicification of bivalves: understanding taphonomic bias. Geological Society of America Abstracts with Programs, 43, 504.

Carter, J.G., Bandel, K., De Buffrénil, V., Carlson, S.J., Castanet, J., Crenshaw, M.A., Dalingwater, J.E., Francillion-Vieillot, H., Géradie, J., Meunier, F.J., Mutvei, H., De Riqlès, A., Sire, J.Y., Smith, A.B., Wendt, J., Williams, A. \& Zylberberg, L. 1990. Glossary of Skeletal Biomineralization. In: Skeletal Biomineralization: Patterns, Processes and Evolutionary Trends (ed. Carter, J.G.), 1, 609-671.

Carez, L. 1881. Étude des Terrains Crétacés et Tertiaires du Nord de l'Espagne. Savy Edit, Paris, 327 p.

Cherns, L. \& Wright, V.P. 2007. Missing molluscs and evidence of large-scale, early skeletal aragonite dissolution in a Silurian sea. Geology, 28, 791-794; doi: 10.1130/0091-7613(2000)28<791:MMAEOL>2.0.CO;2.

d'Archiac, A.M. 1846. Description des fossiles recueillis par M. Thorent dans les couches à Nummulines des environs de Bayonne. Mémoires de la Société géologique de France, 2ème série, 2, 189-217.

d'Archiac, A.M. 1850. Description des fossiles du groupe nummulitique recueillis par M.S.-P. Pratt et M.J. Delbos aux environs de Bayonne et de Dax. Mémoires de la Société géologique de France, 2ème série, 3, 397-456.

Defrance, M. 1827. Serpule. In: Levrault, F.G. (ed.), Dictionnaire des Sciences naturelles, 48, 549-572.

Dickson, J.A.D. 1965. A Modified Staining Technique for Carbonates in Thin Section. Nature, 205, 587; doi: 10.1038/205587a0.

Dodd, M. S., Papineau, D., She, Z., Fogel, M. L., Nederbragt, S. \& Pirajno, F. 2018. Organic remains in late Palaeoproterozoic granular iron formations and implications for the origin of granules. Precambrian Research, 310, 133-152; doi: 10.1016/j.precamres.2018.02.016.

Elorza, J. \& Astibia, H. 2017. El anélido Rotularia spirulaea (Lamarck, 1818) (Polychaeta, Serpulidae) de las margas del Eoceno de la Cuenca de Pamplona (Navarra): microestructura, tafonomía y paleoecología. Spanish Journal of Palaeontology, 32, 343-366.

Fernández López, S.R. 2000. Temas de Tafonomía. Departamento de Paleontología, Universidad Complutense de Madrid, 167 p.

Fozy, I. \& Szente, I. 2014. Fossils of the Carpathian Region. Indiana University Press, Bloomington and Indianapolis, $508 \mathrm{p}$.

Holdaway, H.K. \& Clayton, C.J. 1982. Preservation of shell microstructure in silicified brachiopods from the Upper Cretaceous Wilmington Sands of Devon. Geological Magazine, 119, 371-382; doi: 10.1017/S0016756800026285.

Hosgör , I. \& Okan, Y. 2006. The annelid polychaete Rotularia spirulaea Lamarck, 1818 from the early Middle Eocene (middle-late Cuisian) of Çankırı Basin (Central Anatolia, Turkey). Journal of the Earth Sciences Application and Research Centre of Hacettepe University, 27, 173-179.

Hughes, T.M.M. 1889. On manner of occurrence of Beekite and its bearing upon the origin of siliceous beds of Paleozoic age. Mineralogical Magazine, 8, 265-271.

Ippolitov, A. P., Vinn, O., Kupriyanova, E.K. \& Jäger, M. 2014. Written in stone: history of serpulid polychaetes through time. Memoirs of Museum Victoria, 71, 123-159.

Jacka, A.D. 1974. Replacement of fossils by length-slow chalcedony and associated dolomitization. Journal of Sedimentary Petrology, 44, 421-427.

Jäger, M. 2005. Serpulidae und Spirorbidae (Polychaeta sedentaria) aus Campan und Maastricht von Norddeutschland, den Niederlanden, Belgien und angrenzenden Gebieten. Geologisches Jahrbuch, Reihe A, 157, 121-249.

Krauskopf, KB. 1979. Introduction to Geochemistry (2nd Edition). McGraw-Hill: New York; 1-617.

Lamarck, J.-B. de 1818. Histoire Naturelle des Animaux sans Vertèbres, Présentant les Caractères Généraux et Particuliers de ces Animaux, leur Distribution, leurs Classes, leurs Familles, leurs Genres et la Citation des Principales Espèces qui s'y Rapportent, Précédée d'une Introduction Offrant la Détermination des Caractères Essentiels de l'Animal, sa Distinction du Végétal et des Autres Corps Naturels, enfin, l'Exposition des Principes Fondamentaux de la Zoologie, 5. Déterville et Verdière, Paris, 612 p. 
Linnaeus, C. 1758. Systema Naturae per Regna Tria Naturae: Secundum Classes, Ordines, Genera, Species, cum Characteribus, Differentiis, Synonymis, Locis. Vol. 1, 10th Edition. Impensis Direct. Laurentii Salvii, Holmiæ, Stockholm, 824 p.

Macellari, C.E. 1984. Revision of serpulids of the genus Rotularia (Annelida) at Seymour Island (Antarctic peninsula) and their value in stratigraphy. Journal of Paleontology, 58, 1098-1116.

Mendizábal, J. \& Ruiz de Gaona, M. 1949. Memoria Explicativa de la Hoja 141, Pamplona. MAGNA, 1:50.000. Instituto Geológico y Minero de España. Madrid.

Mikuž, V. 2008. The serpulid worm Rotularia spirulaea from Eocene beds near Gracisce in Istria, Croatia. Geologija, 51, 161-168.

Orue-Etxebarria, X., Lamolda, M. \& Apellaniz, E. 1984. Bioestratigrafía del Eoceno vizcaíno por medio de los foraminíferos planctónicos. Revista Española Micropaleontología, 16, 241-263.

Orue-Etxebarria, X. \& Apellaniz, E. 1985. Estudio del límite Cuisiense-Luteciense en la costa vizcaína por medio de los foraminíferos planctónicos. Newsletters on Stratigraphy, 15, 1-12; doi: 10.1127/nos/15/1985/1.

Papineau, D., She, Z. \& Dodd, M. S. 2017. Chemicallyoscillating reactions during the diagenetic oxidation of organic matter and in the formation of granules in late Palaeoproterozoic chert from Lake Superior. Chemical Geology, 470, 33-54; doi: 10.1016/j.chemgeo.2017.08.021.

Paraguassu, A.B. 1976. Experimental replacement of silica. Revista Brasiliera de Geociências, 6, 89-94.

Payros, A., Pujalte, V., Orue-Etxebarria, X. \& Baceta, J.I. 1997. Un sistema turbidítico Bartoniense de tipo “channel-levee” en la Cuenca de Pamplona: implicaciones tectónicas y paleogeográficas. Geogaceta, 22, 145-148.

Payros, A., Orue-Etxebarria, X. \& Pujalte, V. 2006. Covarying sedimentary and biotic fluctuations in Lower-Middle Eocene Pyrenean deep-sea deposits: Palaeoenvironmental implications. Palaeogeography, Palaeoclimatology, Palaeoecology, 234, 258-276; doi: 10.1016/j.palaeo.2005.10.013.

Payros, A., Pujalte, V., Tosquella, J. \& Orue-Etxebarria, X. 2010. The Eocene storm-dominated foralgal ramp of the western Pyrenees (Urbasa-Andia Formation): An analogue of future shallow-marine carbonate systems? Sedimentary Geology, 228, 184-204; doi: 10.1016/j. sedgeo.2010.04.010.

Plaziat, J.C. 1981. Late Cretaceous to Late Eocene paleogeographic evolution of southwest Europe. Palaeogeography, Palaeoclimatolology, Palaeoecology, 36, 263-320; doi: 10.1016/0031-0182(81)90110-3.

Pujalte, V., Payros, A., Orue-Etxebarria, X. \& Baceta, J.I. 1997. Secuencia evolutiva de los depósitos resedimentados eocenos de Punta Galea, Bizkaia: relevancia para determinación del sentido de transporte de láminas de "slump". Geogaceta, 22, 169-172.
Pujalte, V., Baceta, J.I. \& Payros, A. 2002. Tertiary: Western Pyrenees and Basque-Cantabrian region. In: The Geology of Spain (eds Gibbons, W. \& Moreno, T.). Geological Society of London, London, 293-301.

Rouault, A. 1850. Description des fossiles du terrain éocène des environs de Pau. Mémoires de la Société géologique de France, 2 ème série, 3, 457-502.

Ruiz de Gaona, M. 1946. El terciario numulítico fértil de Guecho (Vizcaya). Notas y Comunicaciones, 16, 185-192.

Ruiz de Gaona, M. 1947a. El Bartoniense de la Cuenca de Pamplona. Notas y Comunicaciones del Instituto Geológico y Minero de España, 17, 155-165.

Ruiz de Gaona, M. 1947b. Sobre el Eoceno de Urbasa a lo largo de la carretera provincial de Olazagutía a Estella. Estudios Geológicos, 5, 179-208.

Ruiz de Gaona, M. \& Colom, G. 1950. Estudios sobre las sinecias de los foraminíferos eocénicos de la vertiente meridional del Pirineo (Cataluña-Vizcaya). Estudios Geológicos, 12, 293-434.

Savazzi, E. 1995. Morphology and mode of life of the polychaete Rotularia. Paläontologische Zeitschrift, 69, 73-85; doi: 10.1007/BF02985975.

Schmidt, W.J. 1955. Nomenklatur und Systematik der Serpuliden-Gattung Rotularia DeFrance (Tubulostium Stoliczka). Mitteilungen der Geologischen Gesellschaft in Wien, 47, 159-182.

Schmitt, J.G. \& Boyd, D.W. 1981. Patterns of silicification in Permian pelecypods and brachiopods from Wyoming. Journal of Sedimentary Research, 51, 1297-1308.

Seilacher, A., Olivero, E.B., Butts, S.H. \& Jäger, M. 2008. Soft-bottom tube worms: from irregular to programmed shell growth. Lethaia, 41, 349-365; doi: 10.1111/j.1502 3931.2008.00092.x.

Seilacher, A. \& Gishlick, A.D. 2014. Morphodynamics. CRC Press. Taylor y Francis Group, 531 p.

Serra-Kiel, J., Hottinger, L., Caus, E., Drobne, K., Ferrandez, C., Jauhri, A.K., Less, G., Pavlovec, R., Pignatti, J., Samso, J.M., Schaub, H., Sirel, E., Strougo, A., Tambareau, Y., Tosquella, J. \& Zakrevskaya, E. 1998. Larger foraminiferal biostratigraphy of the Tethyan Paleocene and Eocene. Bulletin de la Société géologique de France, 169, 281-299.

Stevens, G.R. 1967. Upper Jurassic fossils from Ellsworth Land, West Antarctica, and notes on Upper Jurassic biogeography of the South Pacific Region. New Zealand Journal of Geology and Geophysics, 10, 345-393.

Vinn, O. 2008. Tube ultrastructure of the fossil genus Rotularia Defrance, 1827 (Polychaeta, Serpulidae). Journal of Paleontology, 82, 206-212; doi: 10.1666/06125.1 .

Winfree, A.T. 1984. The Prehistory of the BelousovZhabotinsky Oscillator. Journal of Chemical Education, 61, 661-663.

Wrigley, A. 1951. Some Eocene serpulids. Proceedings of the Geologists Association of the United Kingdom, 62, 177-197. 